\title{
Validade e confiabilidade de software com realidade virtual como tecnologia assistiva para pessoas com distrofia muscular de Duchenne
}

\author{
Tese apresentada à Faculdade de Medicina \\ da Universidade de São Paulo para obtenção \\ do título de Doutor em Ciências \\ Programa de Ciências da Reabilitação \\ Orientador: Prof. Dr. Carlos Bandeira de \\ Mello Monteiro
}

São Paulo 


\title{
Validade e confiabilidade de software com realidade virtual como tecnologia assistiva para pessoas com distrofia muscular de Duchenne
}

\author{
Tese apresentada à Faculdade de Medicina \\ da Universidade de São Paulo para obtenção \\ do título de Doutor em Ciências \\ Programa de Ciências da Reabilitação \\ Orientador: Prof. Dr. Carlos Bandeira de \\ Mello Monteiro
}

São Paulo 


\section{Dados Internacionais de Catalogação na Publicaçăo (CIP)}

\section{Preparada pela Biblioteca da}

Faculdade de Medicina da Universidade de São Paulo

\section{Creproduçăo autorizada pelo autor}

\section{Massetti, Thais}

Validade e confiabilidade de software com realidade virtual como tecnologia assistiva para pessoas com distrofia muscular de Duchenne / Thais Massetti. -- Săo Paulo, 2019.

Tese (doutorado)--Faculdade de Medicina da Universidade de São Paulo.

Programa de Ciências da Reabilitaçăo.

Orientador: Carlos Bandeira de Mello Monteiro.

Descritores: 1.Distrofias musculares 2.Distrofia muscular de Duchenne 3.Destreza motora 4.Terapia de exposiçăo de realidade virtual 5.Reabilitaçăo 6.Interface usuário-computador 7.Validaçăo de programas de computador $\mathrm{USP} / \mathrm{FM} / \mathrm{DBD}-261 / 19$ 
Nome: THAIS MASSETTI

Título: VALIDADE E CONFIABILIDADE DE SOFTWARE COM REALIDADE VIRTUAL COMO TECNOLOGIA ASSISTIVA PARA PESSOAS COM DISTROFIA MUSCULAR DE DUCHENNE.

Tese apresentada à Faculdade de Medicina da Universidade de São Paulo para obtenção do título de Doutora em Ciências pelo Programa de Ciências da Reabilitação

Aprovado em:

Banca Examinadora

Prof. Dr:

Instituição:

Julgamento:

Profa. Dra.:

Instituição:

Julgamento:

Prof. Dr.:

Instituição:

Julgamento:

Profa. Dra.:

Instituição:

Julgamento: 
"Ser feliz é encontrar força no perdão, esperanças nas batalhas, segurança no palco do medo, amor nos desencontros. É agradecer a Deus a cada minuto pelo milagre da vida." 


\section{AGRADECIMENTOS ESPECIAIS}

Agradeço à minha família, em especial a minha mãe e meu marido pelo incentivo, persistência e fé ao longo do meu percurso.

Aos meus amigos e amigas que tiveram paciência e apoiaram em todos os momentos desta etapa, vivenciando-as comigo, e sempre prontos para os melhores conselhos e cuidados.

Ao meu orientador, Prof. Dr. Carlos Bandeira de Mello Monteiro, pela orientação, dedicação e carinho durante todo o processo, além de todo conhecimento transmitido.

Às colegas de pós-graduação pelo apoio e auxílio em diversos momentos, me levando a acreditar que se tornarão parte de muitos momentos de minha vida, Lilian, Talita, Íbis, Vinicius Alcântara, Laercio Paiva, Fernando Rocha, Claudia Arab e Dafne Herrero.

Meu agradecimento e carinho especial a Dra. Tania Brusque Crocetta pela coragem que me transmitiu em todos esses anos, além do carinho e respeito, a Ms. Regiani Guarnieri que foi uma amiga sem igual nesse processo, e se tornou parte da minha vida, a Professora Cristina Hamamura Moriyama por tudo, por todo carinho e cuidado, além de uma parceria fantástica.

E a todos participantes da pesquisa pela confiança e carinho.

O presente trabalho foi realizado com apoio da Coordenação de Aperfeiçoamento de Pessoal de Nível Superior - Brasil (CAPES) - Código de Financiamento 001 


\section{LISTA DE ABREVIATURAS}

$\begin{array}{ll}\text { a } & \text { Alfa de Crombach } \\ \text { BASSIN } & \text { Bassin Anticipation Timer } \\ \text { BL1 } & \text { Bloco 1 } \\ \text { BL2 } & \text { Bloco 2 } \\ \text { BL3 } & \text { Bloco 3 } \\ \text { BL4 } & \text { Bloco 4 } \\ \text { BRIDGE } & \text { Tarefa de Timing Coincidente Virtual (Bridge) do pacote de jogos } \\ & \text { do Team Bridge Games } \\ \text { CCI } & \text { Coeficiente de Correlação Intraclasse } \\ \text { DMD } & \text { Distrofia Muscular de Duchenne } \\ \text { DP } & \text { Desvio Padrão } \\ \text { DT } & \text { Desenvolvimento Típico } \\ \text { EA } & \text { Erro Absoluto } \\ \text { EC } & \text { Erro Constante } \\ \text { EV } & \text { Erro Variável } \\ \text { IC } & \text { Intervalo de Confiança } \\ \text { LI } & \text { Limite Inferior } \\ \text { LS } & \text { Limite Superior } \\ \text { M } & \text { Média } \\ \text { MFM } & \text { Escala de Medida da Função Motora } \\ \text { MFM D1 } & \text { Escala de Medida da Função Motora em seu domínio 1 } \\ \text { MFM D2 } & \text { Escala de Medida da Função Motora em seu domínio 2 } \\ \text { MFM D3 } & \text { Escala de Medida da Função Motora em seu domínio 3 } \\ \text { MFM tot } & \text { Escala de Medida da Função Motora Total } \\ \text { R } & \text { Retenção } \\ \text { RV } & \text { Realidade Virtual } \\ \text { T } & \text { Transferência } \\ & \end{array}$




\section{LISTA DE FIGURAS}

Figura 1 - Tarefa de Timing Coincidente Virtual (Bridge) do pacote de jogos do Team Bridge Games. Na imagem principal, participante com distrofia muscular de Duchenne durante a execução da tarefa e no detalhe da tela do computador (a) o participante acompanha a descida da bolha, aguardando para reagir no teclado quando ela atingir o alvo última bolha. Em (b), o feedback de erro e em (c), o feedback de acerto

Figura 2 - Timing Coincidente Real (Bassin) com o Bassin Anticipation Timer da Lafayette Instrument Corporation

Figura 3 - Sequência das tarefas no Timing Coincidente do Team Bridge Games (Bridge) e no Bassin Anticipation Timer da Lafayette Instrument Corporation (Bassin) para os grupos de distrofia muscular de Duchenne (DMD) e o controle com desenvolvimento típico (DT) ... 27

Figura 4 - Gráficos e Bland-Altman para as tarefas de timing coincidente do Bridge e Bassin representados para erro absoluto

Figura 5 - Gráficos e Bland-Altman para as tarefas de timing coincidente do Bridge e Bassin representados para erro constante

Figura 6 - Gráficos e Bland-Altman para as tarefas de timing coincidente do Bridge e Bassin representados para erro variável 


\section{LISTA DE TABELAS}

Tabela 1 - Indivíduos com diagnóstico de distrofia muscular de Duchenne participantes do estudo (total de 29 indivíduos)

Tabela 2 - Média, desvio padrão, consistência interna, e validade concorrente dos blocos para as tarefas de timing coincidente em ambos os instrumentos, apresentados por grupo e erros 30

Tabela 3 - Correlações de Pearson entre os resultados dos blocos do Timing Coincidente do Bridge e Bassin em três erros, divididos por grupo de participantes 


\section{RESUMO}

MASSETTI, T. VALIDADE E CONFIABILIDADE DE SOFTWARE COM REALIDADE VIRTUAL COMO TECNOLOGIA ASSISTIVA PARA PESSOAS COM DISTROFIA MUSCULAR DE DUCHENNE [TESE]. SÃO PAULO: FACULDADE DE MEDICINA, UNIVERSIDADE DE SÃO PAULO; 2019.

INTRODUÇÃO: A distrofia muscular de Duchenne (DMD) é uma doença genética recessiva, caracterizada pelo enfraquecimento progressivo e irreversível da musculatura, levando a uma grave incapacidade física. OBJETIVO: Analisar a validade e confiabilidade de uma tarefa de "timing coincidente" realizada em jogo de realidade virtual não imersiva com pessoas com DMD. MÉTODOS: Estudo prospectivo, observacional, não experimental. A amostra foi constituída por 91 participantes, sendo $31 \mathrm{com}$ DMD e $60 \mathrm{com}$ desenvolvimento típico (DT). O jogo "Timing Coincidente" do pacote de jogos Team Bridge Games (Bridge) foi utilizado para validação concorrente com o padrão-ouro Bassin Anticipation Timer (Bassin). RESULTADOS: Bridge e Bassin mostraram consistências internas aceitáveis, variando de $\alpha=0,75$ a $\alpha=0,84$ para o Bridge e $\alpha=0,74$ a $\alpha=0,89$ para o Bassin. $O$ grupo DT apresentou os maiores níveis de consistência interna quando comparados ao grupo DMD. As consistências internas das pontuações do bloco de transferência mostraram os escores mais baixos em ambas as tarefas, com $\alpha=0,75$ para Bridge $e$ $\alpha=0,74$ para Bassin. O resultado da validade convergente entre Bridge e Bassin através do coeficiente de correlação intraclasse mostrou uma excelente confiabilidade com valores variando de 0,66 a 0,74 no grupo DMD e 0,73 a 0,82 no grupo DT para os erros absoluto (EA), constante (EC) e variável (EV). O grupo DMD apresentou excelente correlação apenas nos BI3 e BI4 nos EA e EC, e sem correlação em todos os blocos no EV. CONCLUSÃO: O jogo de Timing Coincidente do "Team Bridge" é uma opção válida de software com realidade virtual como tecnologia assistiva para a mensuração deste tipo de tarefa em indivíduos com DMD.

Descritores: Distrofias musculares; Distrofia muscular de Duchenne; Destreza motora; Terapia de exposição de realidade virtual; Reabilitação; Interface usuáriocomputador; Validação de programas de computador 


\begin{abstract}
MASSETTI T. VALIDITY AND RELIABILITY OF VIRTUAL REALITY SOFTWARE AS ASSISTIVE TECHNOLOGY FOR PEOPLE WITH DUCHENNE MUSCULAR DYSTROPHY [THESIS]. SÃO PAULO: FACULDADE DE MEDICINA, UNIVERSIDADE DE SÃO PAULO; 2019.

INTRODUCTION: Duchenne muscular dystrophy (DMD) is a recessive genetic disease. Characterized by the progressive and irreversible weakness of the musculature, leading to a serious physical disability. OBJECTIVE: To analyze the reliability and validity of a coincident timing instrument of a non-immersive virtual reality task in person with DMD. METHODS: A prospective, observational, nonexperimental design was used. In our study, we analyzed 91 participants, consisted of 31 DMD participants and 60 typically development (TD) participants. To perform the validation, we use two instruments, a gold standard - Bassin Anticipation Timer and the other instrument Team Bridge games. RESULTS: Bridge and Bassin showed acceptable blocks score internal consistencies, ranging from $\alpha=.75$ to $\alpha=.84$ for Bridge, and $\alpha=.74$ to $\alpha=.89$ for Bassin. TD group had higher internal consistency blocks when compared to DMD group. The internal consistencies of the transfer block scores showed the lower scores in both tasks, with $\alpha=.75$ for Bridge and $\alpha=.74$ for Bassin. The comparison results between the Bridge and Bassin in terms of the blocks mean differences correlation coefficients for three types of error (absolute error, constant error and variable error) except for transfer block in $\mathrm{AE}$ and $\mathrm{CE}$, Pearson correlation showed the excellent relationship between blocks for TD group. The DMD group showed excellent relationship only in $\mathrm{BI} 3$ and $\mathrm{BI} 4$ in $\mathrm{AE}$ and $\mathrm{CE}$, and no relationship in all blocks of VE. CONCLUSION: The Coincident Timing game in Team Bridge package is a viable option to coincidence anticipation timing task measurement.
\end{abstract}

Descriptors: Muscular dystrophies; Muscular dystrophy, Duchenne; Motor skills; Reality exposure therapy; Rehabilitation; User-computer interface; Software validation 


\section{SUMÁRIO}

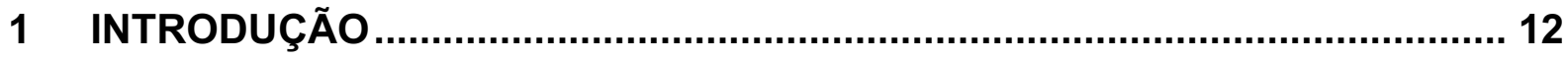

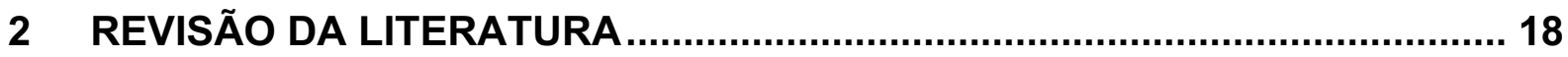

2.1 Realidade Virtual e suas definições................................................... 18

2.2 A validação de instrumentos para uso científico ....................................... 20

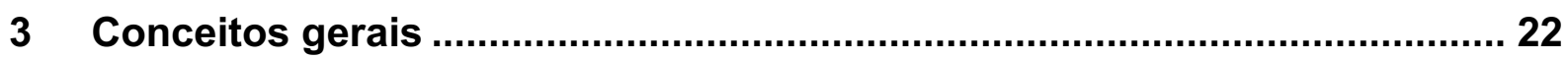

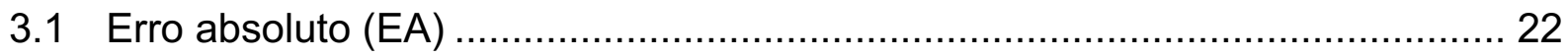

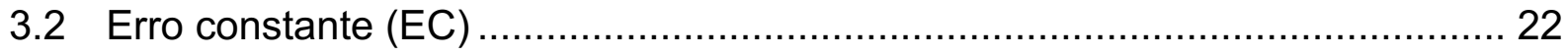

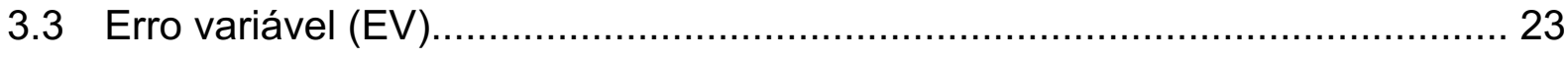

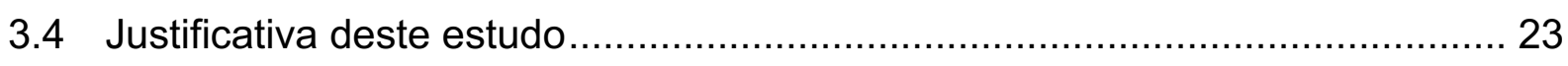

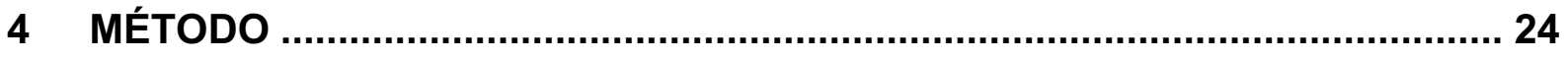

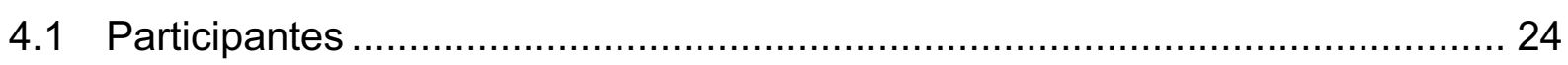

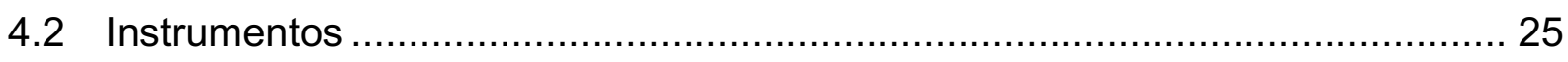

4.2.1 Timing Coincidente Virtual (Bridge) ........................................... 25

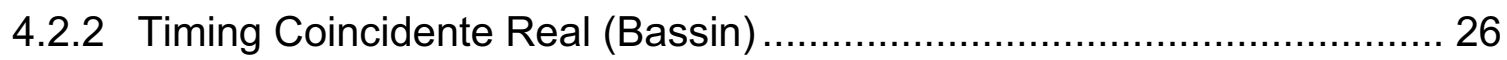

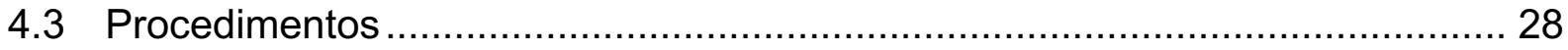

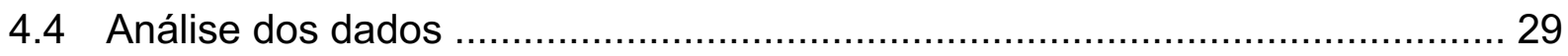

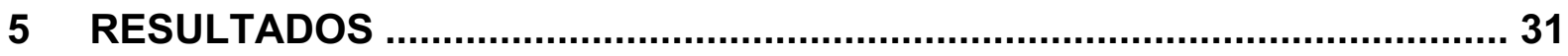

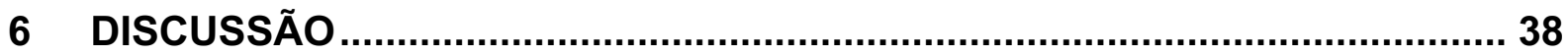

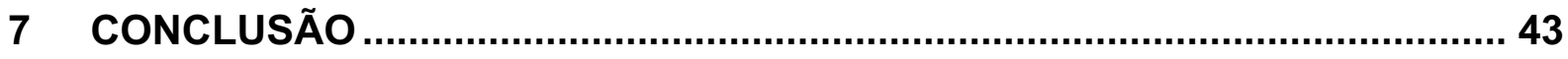

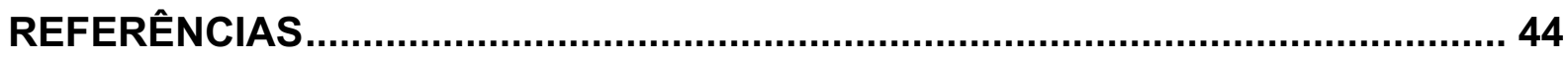

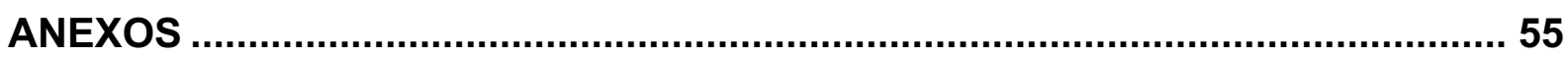

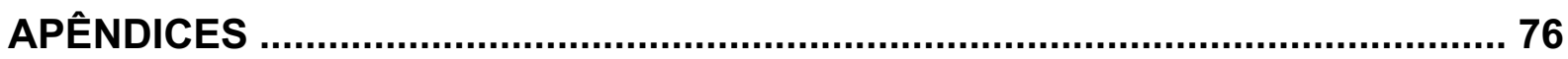




\section{INTRODUÇÃO}

A Distrofia Muscular de Duchenne (DMD) é uma doença de herança recessiva ligada ao $X$ na banda Xp21, levando à ausência da proteína distrofina (FOSTER, POPPLEWELL e DICKSON, 2012), resultando na perda da integridade da membrana fibrosa e ciclos repetidos de necrose e regeneração (GUIRAUD et al., 2015). É considerada uma doença grave e progressiva que afeta 1 em 3600-6000 nascidos vivos do sexo masculino (JUNG et al., 2012).

No indivíduo com DMD, o tecido muscular é gradualmente substituído por tecido conjuntivo fibroso e gordura, levando à fraqueza e contraturas debilitantes. $\mathrm{O}$ envolvimento eventual dos músculos respiratórios e do coração causa insuficiência cardiorrespiratória e morte na segunda a terceira décadas de vida. Embora a base molecular da DMD tenha sido definida há 30 anos, os glicocorticoides e a terapia de suporte continuam sendo o padrão de atendimento (KORNEGAY, 2017).

Os sintomas apresentados incluem atraso motor grosso, anormalidades da marcha, quedas frequentes e dificuldade para levantar-se do chão. Apresentações menos frequentes incluem atrasos na linguagem ou no desenvolvimento global (YIU e KORNBERG, 2015). A maioria dos indivíduos ganham força e habilidades motoras (embora em menor grau que seus pares) até cerca de 6 anos de idade, ocorrendo deterioração progressiva da força, após esse estágio. Sem tratamento, muitos destes indivíduos está sujeita a cadeira de rodas entre 11 e 12 anos de idade (DARRAS et al., 2014).

Não há nenhuma cura conhecida para a DMD mas existem várias pesquisas considerando fenótipo e genótipo (PEDDAREDDYGARI et al., 2011; FOSTER, POPPLEWELL e DICKSON, 2012), alterações cardíacas (BELLO et al., 2012), avaliações clínicas multidisciplinares (BUSHBY et al., 2010), tratamentos terapêuticos (SILVA et al., 2012), tratamento medicamentoso (MALIK, RODINO-KLAPAC e MENDELL, 2012; MERLINI et al., 2012; RAMAN, YACOB e TOBIAS, 2012), além de estudos sobre funcionalidade, autocuidado e função social (VESTERGAARD et al., 2001; VISSER, 2003), análise de diferentes dispositivos de interação de realidade virtual (de FREITAS et al., 2019), aprendizado motor a curto prazo com o uso de realidade virtual e contato real (MASSETTI et al., 2018), entre outros.

No estudo de Birnkrant et al (2018), os autores afirmam que o monitoramento próximo por uma equipe de reabilitação interdisciplinar constitui a base do tratamento, 
e que o tratamento com glicocorticóides pode retardar a progressão da doença e melhorar a função motora a curto prazo. Estudos experimentais com animais demonstraram que o treinamento de resistência isométrica aumentou a força e alterou a histopatologia do músculo esquelético de ratos com deficiência de distrofina (LINDSAY et al, 2019), e que a longevidade dos animais distróficos foi negativamente associada ao esforço muscular independentemente da duração do esforço (HUGHES et al, 2019). Estes são resultados promissores na busca por intervenções para melhora da qualidade de vida desta população.

Devido às dificuldades funcionais apresentadas por indivíduos com DMD o uso de tecnologia assistiva (TA) mostra-se um aliado fundamental. O interesse em utilizar a TA avançou rapidamente durante a última década, como auxiliar no ensino de pessoas com deficiência, tanto de forma permanente quanto temporária. De acordo com Neistadt e Crepeau (2002), a TA pode ser definida como qualquer item, peça ou produto pronto ou feito sob medida para manter ou melhorar as capacidades funcionais das pessoas. O uso de dispositivos de TA é crucial para muitas pessoas com deficiência, pois possibilita sua independência funcional, manutenção da saúde física e mental e autocuidado. Além disso, o uso da TA pode aprimorar a qualidade de vida das pessoas, melhorando a mobilidade, a comunicação e o gerenciamento da casa (BAMER et al., 2010; OKORO et al., 2010). Assim, dispositivos de TA são recursos que contribuem para fornecer ou expandir as habilidades funcionais das pessoas com deficiência, sendo fundamentais para promover maior independência e inclusão social (COOK e HUSSEY, 1995). Shih, Shih e Chu (2010) citam que a modernidade tecnológica pode influenciar diretamente a produção de novas TAs, que possibilitem uma maior função com dispositivos interativos para pessoas com dificuldades motoras. Nesse sentido, o uso de novos dispositivos tecnológicos pode permitir que pessoas com DMD apresentem maior independência em diferentes tarefas funcionais e participação social.

Considerando diferentes possibilidades de TAs, uma nova abordagem utilizada na reabilitação é a proposta pelos ambientes de realidade virtual (RV). Estes ambientes são seguros para praticar habilidades que podem ter diversos riscos no mundo real (STANDEN e BROWN, 2005), além de oferecer muitas possibilidades para melhorar o potencial de reabilitação para pessoas com deficiência motora ou intelectual. Segundo Fernani et al. (2013), a RV e as tecnologias modernas podem ser usados como uma forma de intervenção física ou cognitiva, por meio do uso de jogos e ambientes virtuais para melhorar a funcionalidade. 
Vilozni et al (1994) utilizou jogos para serem controlados pelos esforços respiratórios oferecendo dados e medidas precisas de ventilação e tempo de execução. Os autores concluíram que os jogos computadorizados podem ser aplicados como exercícios com o uso de técnicas respiratórias, melhorando o desempenho respiratório em crianças com DMD que apresentavam deficiência moderada nos testes de função pulmonar. Em um estudo que utilizou a RV como conduta terapêutica, os resultados mostraram uma melhora no desempenho de indivíduos com DMD quando usando uma interface virtual que não requer contato físico, apesar da dificuldade progressiva do movimento e força dos membros superiores, além disso um dispositivo sem contato facilitou a implementação bemsucedida da tarefa proposta, fornecendo evidências para futuras pesquisas usando interfaces virtuais que incentivam o movimento distal e têm o potencial de permitir melhorias nas tarefas diárias para os indivíduos com DMD (de FREITAS et al, 2019).

O estudo de Capelini et al (2017) mostrou que indivíduos com DMD apresentaram melhor desempenho em um protocolo de aprendizado motor a curto prazo usando um smartphone, afirmando que essa tecnologia poderia ser usada para promover a melhora da função nessa população.

Munih et al (2010) avaliaram a capacidade de força de membros superiores em 32 indivíduos com DMD e apresentaram uma nova técnica para avaliação funcional por meio de exercícios em ambiente virtual com capacidade máxima de esforço. $A$ medição consistiu em um simulador de RV capaz de fornecer feedback tátil, visual e auditivo. Os resultados mostraram a validação desta técnica de avaliação e que o simulador de RV utilizado apresentava os critérios necessários para avaliar a capacidade de força em indivíduos com DMD.

Hashimoto et al (2010) desenvolveram um sistema de interação motora em interface cérebro-computador com objetivo de verificar a comunicação de indivíduos com DMD por meio de um eletroencefalograma (EEG), junto a utilização de uma plataforma de RV. Os autores relataram que um indivíduo com DM severa utilizou o sistema por $1 \mathrm{~h}$ por dia, e em seguida, continuou a mesma metodologia 2 vezes por mês em casa. Os dados demonstraram mudanças no desempenho em longo prazo. Estes resultados mostraram que indivíduos com DM foram capazes de aprender a controlar seu sinal EEG e se comunicar com outros usuários por meio da utilização de navegação em ambiente virtual, sugerindo que a RV tem potencial para fornecer uma oportunidade para facilitar a comunicação pra as pessoas com deficiências físicas. 
Existe uma crescente utilização de tarefas virtuais para reabilitação, porém, os jogos comerciais disponíveis no mercado apresentam dificuldades para adaptação às pessoas com deficiência, surgindo a necessidade da criação de tarefas específicas e que possibilitem o controle das variáveis e fornecimento de relatório para a equipe multidisciplinar. Conforme apresentado por Crocetta et al (2017) as dificuldades de tarefas virtuais por jogos comerciais são a falta de controle por parte do pesquisador da métrica utilizada pelo jogo, além da ausência dos resultados gerados pelo participante e da pontuação geral. Os autores descrevem uma plataforma de jogos virtuais com parâmetros que podem ser controlados pelos pesquisadores durante a utilização para obter a execução sequencial dos movimentos realizados pelos participantes.

Devido a necessidade de acompanhamento do desempenho e utilização de tarefas em ambientes virtuais pela equipe multidisciplinar, começaram a surgir softwares de jogos especialmente criados para pessoas com deficiência. Segundo Peijnenborgh et al (2016) recentemente tem havido um aumento no desenvolvimento e uso de tarefas computadorizadas para intervenção e medição das habilidades neurocognitivas e motoras, e estes resultados são promissores no campo da intervenção.

Artilheiro et al (2018) afirmam que poucos biomarcadores envolvendo funções de membros superiores estão atualmente disponíveis para a tomada de decisão na pesquisa e na prática clínica com pacientes com DMD. Assim, a descrição do desempenho cronometrado e o estabelecimento de categorias de desempenho podem ajudar os clínicos a desenvolver estratégias de tratamento clínico, fazendo com que as informações quantitativas envolvendo a função motora sejam úteis para monitorar a progressão da DM.

Desta forma, uma nova possibilidade que surge é a criação de tarefas virtuais que possam mensurar as dificuldades apresentadas pela pessoa com deficiência. Uma tarefa utilizada em pesquisas clínicas e que oferece informações importantes sobre a capacidade perceptual-motora, inclusive com informações que podem auxiliar na funcionalidade do dia a dia são tarefas de timing coincidente.

Uma tarefa de timing coincidente ou timing antecipatório é utilizada para testar a acuidade visual que está relacionada com a coordenação óculo-manual e sua antecipação para acurácia visual (AK e KOCAK, 2010; AKPINAR et al, 2012). Belisle (1963) definiu a tarefa de Timing coincidente como a capacidade perceptual-motora 
para executar uma resposta motora em sincronia com a chegada de um objeto externo em um determinado ponto. Ela se refere a habilidade de julgar quando um estímulo em movimento irá coincidir com um alvo (SANDERS, 2011), e isto está profundamente relacionada a inúmeras atividades da vida diária (DUNCAN et al, 2015). Uma tarefa de timing coincidente é utilizada para compreender o sistema viso-motor, que envolve como o controle motor processa as informações na interceptação de um objeto em movimento (NAKAMOTO et al, 2015), e como as pessoas fazem este julgamento em cada movimento para beijar outra pessoa, apertar as mãos, pegar um copo, agarrar uma bola ou caminhar através de ruas cheias de pessoas (SANDERS, 2011).

Uma versão de software com esta tarefa foi testada em pessoas com paralisia cerebral por (de MELLO MONTEIRO et al, 2014), com síndrome de Down (de MELLO MONTEIRO et al, 2017) e também em pessoas com DMD (Quadrado et al, 2017). Uma versão com utilização de objetos 3D e interfaces de RV foi apresentada por Crocetta et al. (2017) para uso em diversas populações e em seguida, validado em uma população de adultos saudáveis (CROCETTA et al., 2019). Esta versão possibilitou que Bezerra et al. (2018) demonstrasse que o ambiente virtual permitiu uma melhora no desempenho com um aprendizado motor de curto prazo em uma população de idosos e possibilitou o desenvolvimento de protocolo de intervenção apresentado por Antunes et al. (2017).

Poucos trabalhos têm como proposta testar e validar novos instrumentos tecnológicos para oferecer respaldo teórico-prático justificando benefícios e viabilizando a utilização para pessoas com DMD. As questões relacionadas às validações de instrumentos que utilizam tarefas em ambientes virtuais têm surgido na medida que há maior interesse sobre o impacto de sua utilização para pessoas com deficiência. Alguns estudos relatam a importância de instrumentos especialmente desenvolvidos e/ou validados especificamente para a população com DMD devido suas características particulares, destacando-se os estudos realizados por Hukuda et al. (2013), de Carvalho et al. (2015) e Nascimento et al. (2016).

Buscando aumentar o leque de instrumentos para a população com DMD é que propomos esta pesquisa com o objetivo de analisar a confiabilidade e a consistência interna de uma tarefa de timing coincidente em computador (tarefa em 3D) e sua validação concorrente com um instrumento real, o "Bassin Anticipation Timer (Lafayette Instrument Corporation), considerado como "padrão ouro" pra tarefas de timing coincidente. 
Sullivan (2011) e Lai (2013) afirmam que todos os instrumentos devem ser avaliados em sua confiabilidade e validade antes do seu uso efetivo, para garantir que o instrumento usado de fato mede o que se propõe a medir, e com isso aumentar a credibilidade do estudo.

Assim, para analisar a confiabilidade, a consistência interna e a validade de um software com uma tarefa de timing coincidente, pessoas com DMD e pessoas sem alteração da postura e movimento (grupo controle) foram avaliadas usando duas tarefas similares em ambientes diferentes (real e virtual). O importante é avaliar se esta tarefa em ambiente virtual pode ter sua confiabilidade, consistência interna e validade confirmados para uso com os indivíduos com DMD, partindo do pressuposto que os resultados demonstrarão medidas sem erros, o que significaria que o software é capaz de mensurar as mesmas pessoas com a mesmo desempenho que testes equivalentes (concorrência), além de verificar sua confiabilidade e consistência interna. Caso a hipótese seja comprovada, ter-se-á um software válido que além de recurso de Tecnologia Assistiva, permita a mensuração do "timing coincidente" da pessoa com DMD, o que não só ajudará em pesquisas futuras, mas também como um sistema de avaliação na prática clínica. 


\section{REVISÃO DA LITERATURA}

\subsection{REALIDADE VIRTUAL E SUAS DEFINIÇÕES}

A realidade virtual $(R V)$ é uma tecnologia de interface computacional que cria um ambiente simulado artificial tridimensional, sendo uma forma de os humanos se conectarem visualmente, manipularem e interagirem com os computadores (ARANE, BEHBOUDI e GOLDMAN, 2017; MASSETTI et al., 2018). Pode ser vista como uma forma avançada de interação humano-computador que permite aos usuários imergirem em ambientes virtuais sintéticos gerados por computador (RIZZO e SHILLING, 2017). A criação de uma experiência em RV pode ser realizada usando combinações de uma ampla variedade de dispositivos de interação, sistemas de exibição sensorial e conteúdo apresentado no ambiente virtual (MASSETTI et al., 2018).

A RV se presenta como uma abordagem relativamente recente que permite a prática simulada de tarefas funcionais em uma dosagem mais alta do que as terapias tradicionais (FUNG et al., 2012; DEMAIN et al., 2013). A RV tem sido definida como o uso de simulações interativas criadas com hardware e software para apresentar aos usuários oportunidades de se envolver em ambientes que se pareçam com objetos e eventos do mundo real (WEISS et al., 2004).

Conforme Burdea et al. (2013), essa tecnologia oferece vantagens em relação aos métodos convencionais por possibilitar a participação de pessoas com deficiências: representações visuais, auditivas e sinestésicas que motivam o participante e tornam a atividade mais empolgante; feedback imediato e medidas objetivas dos movimentos, como, por exemplo, velocidade dos membros, amplitude de movimento, taxas de acerto e/ou erro, pontuações em jogos, entre outros; armazenamento dos dados coletados no computador, no qual ocorre a simulação e possibilidade de disponibilizá-los na Internet para acesso remoto; graduação da complexidade das tarefas de forma a aumentar ou diminuir a carga cognitiva; realização de atividades domiciliares não-assistidas, a fim de diminuir a dependência pelo apoio de outros.

Durante a prática de atividade física, esporte e reabilitação motora das capacidades funcionais, o uso de RV pode proporcionar diversão como também estimular às funções cognitivas básicas, tais como atenção, concentração, memória, planejamento, cálculo, entre outras atividades que se relacionam àquelas realizadas durante os jogos (COYNE, 2008; GOLOMB et al., 2010). 
Os sistemas de RV classificam-se em imersiva, semi-imersiva e não-imersiva conforme os níveis de imersão do usuário (KIRNER e SISCOUTTO, 2007). Esta classificação varia de acordo com a sensação de presença do usuário dentro do ambiente virtual. Um software para RV gera um mundo virtual que pode estar acoplado tanto na tela do computador como a dispositivos específicos (capacetes de visualização, sensores de movimento, controles reativos, sons, etc) e permitem ao usuário a imersão no ambiente virtual por meio de diferentes canais sensoriais (da SILVA et al., 2015).

Sistemas de RV imersivos são projetados para incluir entradas visuais e auditivas do ambiente real do usuário. Geralmente, esses sistemas incorporam a detecção de movimento e permitem que o usuário interaja com um mundo virtual responsivo, por exemplo, Oculus Rift ${ }^{\mathrm{TM}}$ ou HTC Vive Pro ${ }^{\mathrm{TM}}$, que fornecem feedback multissensorial por meio de um sensor acoplado a esses dispositivos montado na cabeça do usuário (BRYANT, BRUNNER e HEMSLEY, 2019).

A imersão também pode ser alcançada através do uso do CAVE Automated Virtual Environment (CAVE), que opera através da projeção de um ambiente virtual em todas as superfícies dentro de um espaço fechado, ou seja, o piso, teto e pelo menos três paredes de uma sala (BRYANT, BRUNNER e HEMSLEY, 2019). No Brasil, conhecida como CAVERNA digital, começou a ser construída em 2000 por pesquisadores do Laboratório de Sistemas Integráveis, vinculado à Escola Politécnica da USP (LSI-EPUSP). A CAVERNA Digital além das projeções imersivas em 3 dimensões possibilitada por 5 telas de $3 \times 3 \mathrm{~m}$ que a formam, também pode receber interfaces que estimulem o som e o tato, como caixas de som estéreo e equipamentos de force feedback: por isso é um sistema de realidade virtual que possibilita alto envolvimento do usuário (http://www.Isi.usp.br/ rv/p/cave_lab_p.html). Esse exemplo difere dos citados anteriormente, uma vez que que o usuário tem a visão livre de seu próprio corpo e ambiente imediato do mundo real, criando o que às vezes é conhecido como uma realidade mista (MADARY e METZINGER, 2016).

A RV semi-imersiva sobrepõe imagens virtuais a imagens reais para aumentar o conteúdo informativo (AN e PARK, 2018). A imersão não é total, pois é possível ao usuário observar o mundo virtual ao mesmo tempo que o mundo real que circunda este dispositivo de visualização, impedindo que o usuário se sinta completamente imerso dentro do ambiente virtual, já que o dispositivo não é capaz de isolá-lo das influências externas que ocorrem ao seu redor (Da SILVA et al., 2015). A RV semi- 
imersiva tem sido utilizada para ensinar crianças a atravessarem a rua de maneira segura (MCCOMAS, MACKAY e PIVIK, 2002; THOMSON et al., 2005; SCHWEBEL, MCCLURE e SEVERSON, 2014; SCHWEBEL et al., 2016) ou alfabetização de crianças com deficiência intelectual (GUARNIERI et al., 2019).

Há também a realidade virtual não-imersiva, que corresponde a interação em que o usuário é parcialmente transportado para o mundo virtual por janelas de interfaces gráficas e faz uso de dispositivos convencionais como monitores de computador, jogos eletrônicos na televisão ou projetores, nos quais a sensação de presença do usuário está predominantemente no mundo real interagindo com objetos ou símbolos no mundo virtual.

\subsection{A VALIDAÇÃO DE INSTRUMENTOS PARA USO CIENTÍFICO}

Segundo da Silva et al. (2015) e de Santana et al. (2015), a validação de um instrumento configura-se como um processo de investigação para demonstrar a acurácia e precisão de um instrumento de medida. Esse processo visa examinar a precisão de uma determinada predição ou inferência realizada a partir dos escores de um teste. O processo de validação não se exaure, ao contrário, pressupõe continuidade e deve ser repetido inúmeras vezes para o mesmo instrumento. Validase não propriamente o teste, mas a interpretação dos dados decorrentes de um procedimento específico (RAYMUNDO, 2009).

A validação concorrente é obtida quando os resultados obtidos por meio de um teste válido de "padrão-ouro" servem de critério para determinar a validade de um novo instrumento. Portanto, é muito importante estudar sua precisão em termos de nível de concordância e validade concorrente com ferramentas de medição bem estabelecidas antes de utilizá-lo em situações clínicas (DOLATABADI, TAATI e MIHAILIDIS, 2016).

Confiabilidade pode ser visto em termos de consistência: o instrumento consistentemente mede o que pretende medir? Não é possível calcular a confiabilidade diretamente; no entanto, existem alguns estimadores gerais que podem ser encontrados na literatura:

Confiabilidade de formas paralelas ou concorrente: é a confiabilidade de dois testes construídos da mesma forma, com o mesmo conteúdo (BIDDIX, 2009). Neste estudo nós consideramos como validade concorrente. 
Consistência interna: é a consistência de resultados entre itens, frequentemente medido pelo alfa de Cronbach (BIDDIX, 2009). Ele calcula as correlações entre todas as variáveis, em cada combinação; uma estimativa de confiabilidade alta deve estar o mais próximo possível de "1" (SULLIVAN, 2011). 


\section{CONCEITOS GERAIS}

Uma abordagem tradicional do desempenho motor humano usa o erro relativo das pontuações para um determinado critério (CRABTREE e ANTRIM, 1988). O desempenho em uma tarefa de timing coincidente (TTC) é medida usando pontuações dos erros com valores negativos representando que o tempo de chegada foi subestimado (antecipado) e a pontuação positiva como superestimada (atrasado). Nos estudos com esta tarefa, os autores reportam um ou mais das seguintes medidas de erro: erro absoluto (EA), média do erro sem sinal; erro constante (EC), média do erro negativo ou positivo algebricamente assinalado; e erro variável (EV), que é quão repetidamente próximo o participante está da sua média estimada para o tempo coincidente. EA e EC medem a acurácia, enquanto o EV mede a precisão ou consistência (SANDERS, 2011; SANDERS e SINCLAIR, 2011; MASAKI et al, 2012).

\subsection{ERRO ABSOLUTO (EA)}

EA não leva em conta a direção de cada resposta até o alvo, e representa a medida tradicional da acurácia geral do desempenho (GUTH, 1990).

$$
\mathrm{EA}=\frac{\sum_{\mathrm{i}=1}^{\mathrm{n}} \mid \mathrm{x}_{\mathrm{i}}-\text { Critério } \mid}{\mathrm{n}}
$$

\subsection{ERRO CONSTANTE (EC)}

EC é obtido pela média aritmética dos valores de erro, considerando o sinal algébrico (negativo ou positivo) em uma série de tentativas (blocos de tentativas). Representa se a direção do erro é de antecipação ou atraso (de MELLO MONTEIRO et al, 2017).

$$
E C=\frac{\sum_{i=1}^{n} x_{i}-\text { Critério }}{n}
$$




\subsection{ERRO VARIÁVEL (EV)}

EV é obtido a partir do desvio padrão da média de resposta dos participantes; isto representa a variabilidade/inconsistência das respostas (LYONS, AL-NAKEEB e NEVILL, 2008).

$$
E V=\sqrt{\left[\frac{\left(\sum_{i=1}^{n} x_{i}-C r i t e ́ r i o\right)^{2}}{n}\right]-(E C)^{2}}
$$

\subsection{JUSTIFICATIVA DESTE ESTUDO}

Nesse contexto, o uso de tecnologias de realidade virtual tem como alvo um caminho para reabilitação de pessoas com doenças neuromusculares, como é o caso da distrofia muscular de Duchenne. Portanto, verificar a consistência interna, confiabilidade e validade de instrumentos que atuem nesse grupo é de suma importância para investigar se estes apresentam resultados consistentes e respondem a todos os aspectos de seu objeto, observando seu conteúdo e relevância dos objetivos a medir (RAYMUNDO, 2009). 


\section{MÉTODO}

Trata-se de um estudo metodológico, com foco na validação de jogos sérios com uso de realidade virtual com diferentes dispositivos para aquisição do movimento.

Estudo prospectivo, observacional, não experimental.

Esta pesquisa obedece aos princípios éticos para pesquisas com seres humanos, conforme resolução do Conselho Nacional de Saúde 466/12 e aprovada pelo comitê de ética da Universidade de São Paulo - CAAE: 64307417.3.0000.0065. Os participantes e seus pais foram informados de todas as tarefas que seriam necessárias e dos objetivos do estudo. Todos os participantes maiores de 18 anos assinaram o Termos de Consentimento Livre e Esclarecido. Aqueles com menos de 18 anos assinaram o Termo de Assentimento Livre e Esclarecido e seus pais ou representantes legais o Termo de Consentimento Livre e Esclarecido.

\subsection{PARTICIPANTES}

A amostra do estudo foi composta por 91 participantes divididos em: 31 participantes no grupo experimental - Grupo distrofia muscular de Duchenne (DMD) provenientes de uma instituição pública de reabilitação (AACD, São Paulo, Brasil) e 60 participantes do grupo controle, com desenvolvimento típico (DT), provenientes de escolas públicas regulares (São Paulo, Brasil). Os participantes do grupo DMD variaram em idade entre 8 e 18 anos, com média de 13,78 anos ( $D P=2,98$ ). Todos os indivíduos foram considerados elegíveis para o estudo se tiveram o diagnóstico de DMD confirmado por método molecular e / ou pela expressão proteica do músculo esquelético. Dois dos participantes foram excluídos da análise estatística, pois não concluíram todas as etapas da tarefa. Os participantes do grupo DT variaram em idade entre 10 e 18 anos, com média de 14,72 anos (DP =2,28). Os critérios de exclusão foram distúrbios na função cognitiva que impediriam a compreensão das instruções da tarefa proposta.

Para a caracterização de indivíduos com DMD, foi aplicada a escala de Vignos (VIGNOS e ARCHIBALD, 1960) que caracteriza o estadiamento da doença, de acordo com os marcos da evolução, utilizando uma pontuação de 1 a 10 , em que quanto maior a nota, maior é a deficiência do paciente, ou seja, 1-caminhadas e subidas de escadas não assistidas e 10-confinado à cama. A escala de Medição da Função Motora (MFM), que avalia quantitativamente a função motora, também foi usada para 
descrever os déficits motores, constituídos por 32 tarefas, divididas em três domínios que fornecem um perfil detalhado da deficiência física: (D1) em pé e transferência; (D2) capacidade motora axial e proximal e (D3) capacidade motora distal (BERARD et al., 2005) (ver Tabela 1).

Tabela 1 - Indivíduos com diagnóstico de distrofia muscular de Duchenne participantes do estudo (total de 29 indivíduos)

\begin{tabular}{lccccccc}
\hline & $\begin{array}{l}\text { Idade } \\
\text { (anos) }\end{array}$ & Vignos & $\begin{array}{l}\text { MFM } \\
\text { D1 }\end{array}$ & $\begin{array}{l}\text { MFM } \\
\text { D2 }\end{array}$ & $\begin{array}{l}\text { MFM } \\
\text { D3 }\end{array}$ & $\begin{array}{l}\text { MFM } \\
\text { TOTAL }\end{array}$ & EK \\
\hline Média & 14,72 & 6 & 18,76 & 76,00 & 81,90 & 55,01 & 6,57 \\
Mín/Máx & $10 / 18$ & $2 / 8$ & $0 / 69$ & $41 / 100$ & $47 / 100$ & $28 / 95$ & $2 / 15$ \\
Desvio padrão & 2,28 & 2,32 & 24,48 & 18,99 & 13,95 & 19,28 & 4,78 \\
\hline
\end{tabular}

Vignos: Escala Vignos; MFM: Escala de Medição da Função Motora; EK: Egen Klassifikation; D1: em pé e transferência; D2: capacidade motora axial e proximal; D3: capacidade motora distal; Mín/Máx: Mínimo/Máximo.

\subsection{INSTRUMENTOS}

\subsubsection{Timing Coincidente Virtual (Bridge)}

O jogo "Timing coincidente" do pacote de jogos Team Bridge Games foi validado em uma amostra de 224 indivíduos saudáveis por Crocetta et al. (2019).

Este pacote de jogos foi criado em parceria com o grupo de Sistemas da Informação da Escola de Artes, Ciências e Humanidades (EACH-USP) que propõe a tarefa de "timing" coincidente em 3D no computador (Figura 1). Neste ambiente virtual são exibidos na tela do computador, 10 bolhas em 3D que acendem (luz vermelha) em sequência até atingir a última bolha que é considerada o alvo. O participante tem feedback imediato de acerto ou erro da tarefa por meio de sons e cores diferentes, previamente demonstrados. O registro do movimento é obtido pela barra de espaço do teclado do computador. Caso o participante pressione o teclado no mesmo momento da chegada do estímulo ao alvo, as barras laterais alteram as cores para verde e uma bolha verde também é apresentada ao lado da tarefa - feedback de acerto, no entanto caso o participante atrase ou adiante o pressionamento, uma bolha 
vermelha é mostrada ao lado da tarefa e as barras são apresentadas em vermelhofeedback de erro (Figura 1).

Um artigo para explicar melhor o software com os detalhes sobre o jogo e a plataforma que engloba outras tarefas foi publicado por Crocetta et al. (2017).

Figura 1 - Tarefa de Timing Coincidente Virtual (Bridge) do pacote de jogos do Team Bridge Games. Na imagem principal, participante com distrofia muscular de Duchenne durante a execução da tarefa e no detalhe da tela do computador (a) o participante acompanha a descida da bolha, aguardando para reagir no teclado quando ela atingir o alvo - última bolha. Em (b), o feedback de erro e em (c), o feedback de acerto.

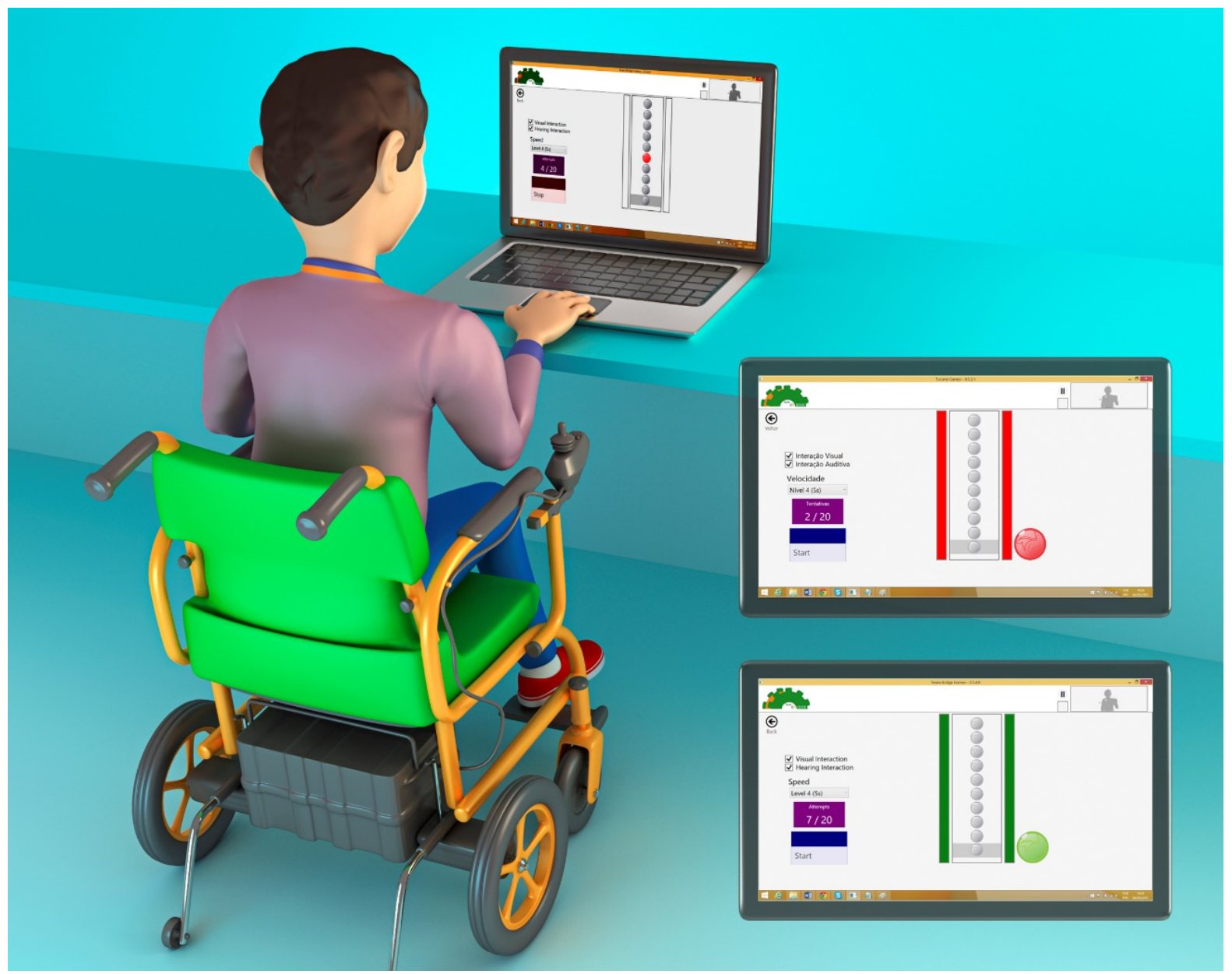

Fonte: Do próprio autor.

\subsubsection{Timing Coincidente Real (Bassin)}

O Bassin Antecipation Timer (Bassin) foi desenvolvido para testar a área de acuidade visual relacionada com a coordenação óculo-manual e a antecipação. $O$ participante é instruído a acompanhar uma luz que acende de forma sequencial ao longo de uma barra metálica, devendo antecipar a luz que atinge o alvo pressionando 
um botão de forma a coincidir com a chegada da luz (LAFAYETTE, 2008). O Bassin armazena a diferença de tempo entre a resposta do participante com a chegada da luz, indicando se a resposta foi antecipada ou atrasada. Para este estudo foi utilizado o modelo 35575, comercializado pela Lafayette Instrument Corporation (Figura 2).

Figura 2 - Timing Coincidente Real (Bassin) com o Bassin Anticipation Timer da Lafayette Instrument Corporation.

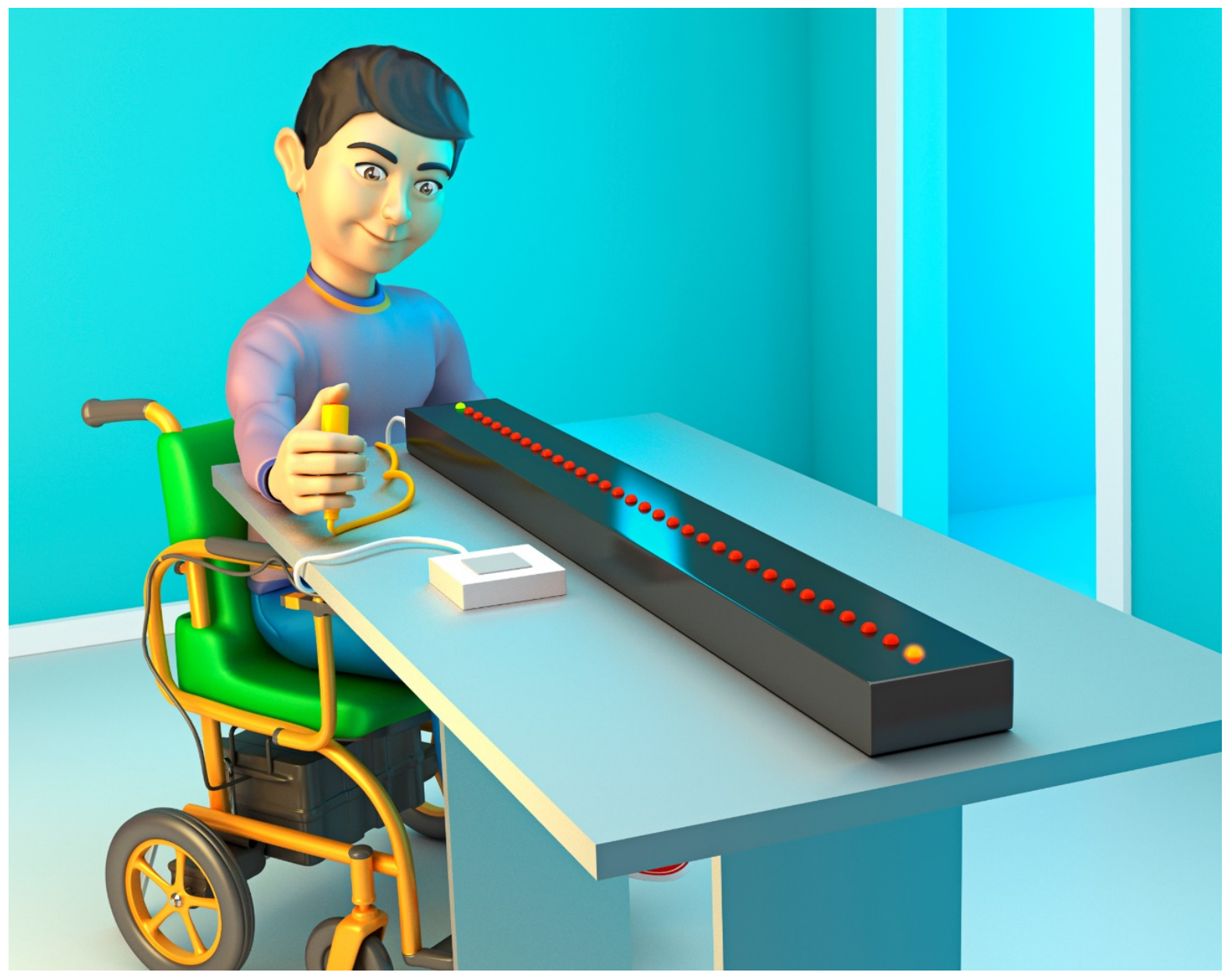

Fonte: Do próprio autor. 


\subsection{PROCEDIMENTOS}

As coletas foram realizadas em ambiente reservado, com a presença de apenas um pesquisador. Cada indivíduo foi avaliado individualmente em uma sala silenciosa no jogo Timing Coincidente do Team Bridge Games (Bridge) e no Bassin Anticipation Timer da Lafayette Instrument Corporation (Bassin) no mesmo dia. A ordem de administração dos dois testes foi aleatorizada (Figura 3).

Os participantes foram acomodados confortavelmente em uma cadeira com ajuste de altura ou permaneceram em sua cadeira para aqueles que apresentaram o uso de cadeira de rodas.

Primeiramente foi apresentado o TCLE e o TALE (de acordo com a idade do participante) explicando a pesquisa, seus objetivos, hipóteses e resultados esperados. Sempre com a preocupação de apresentar de forma clara e respeitando o nível de entendimento do participante e/ou seus representantes legais. Após a assinatura do TCLE e TALE, a tarefa foi demonstrada verbalmente pelo pesquisador. O tempo para as coletas não foi inferior a 20 minutos e não superior a 45 minutos.

Figura 3 - Sequência das tarefas no Timing Coincidente do Team Bridge Games (Bridge) e no Bassin Anticipation Timer da Lafayette Instrument Corporation (Bassin) para os grupos de distrofia muscular de Duchenne (DMD) e o controle com desenvolvimento típico (DT).

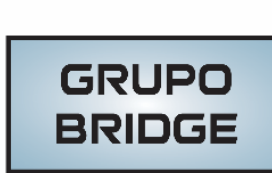

Fonte: Do próprio autor.

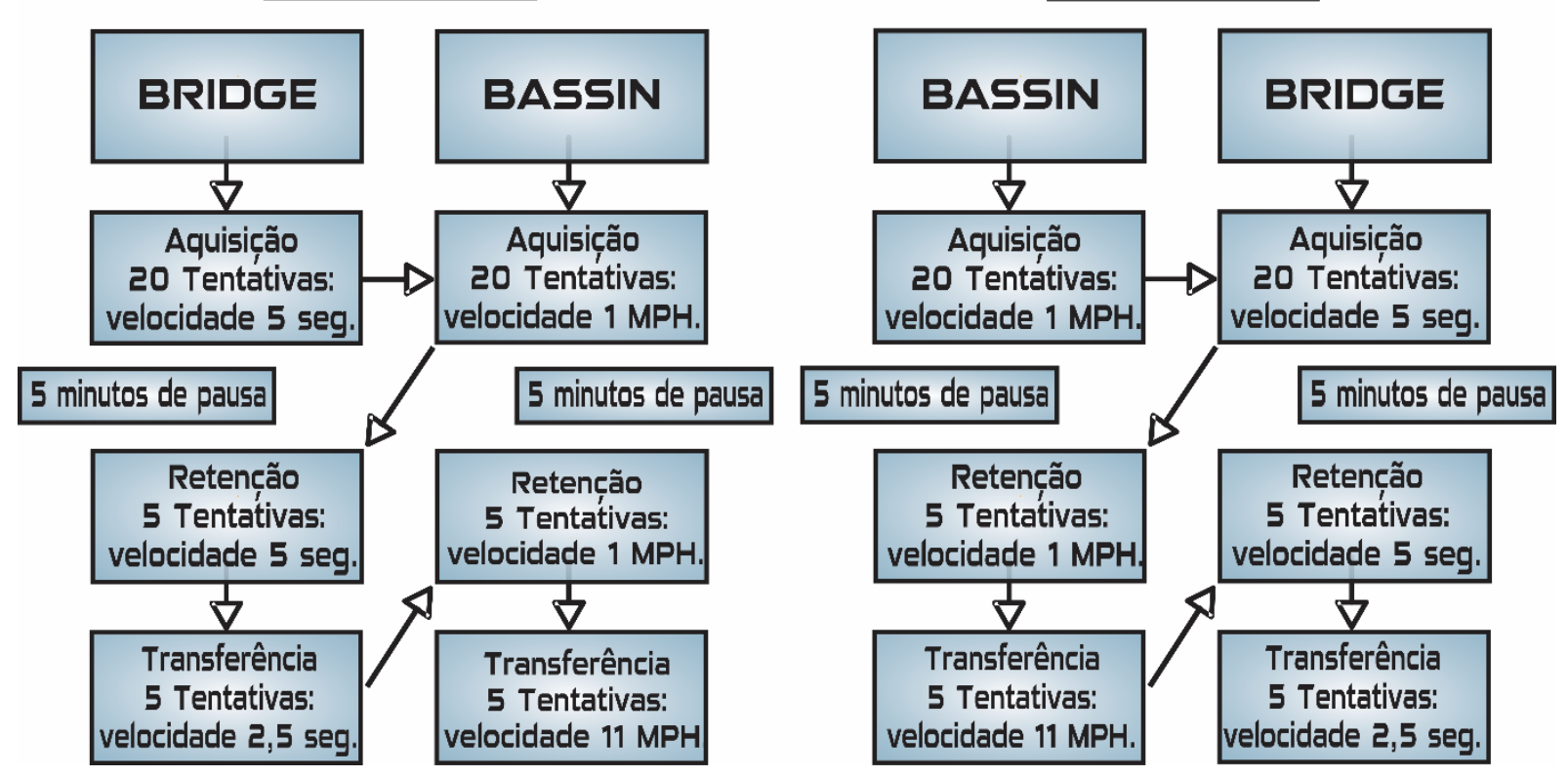

\section{DMD / DT

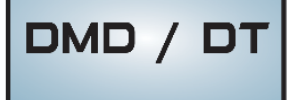

GRUPO

BASSIN 


\subsection{ANÁLISE DOS DADOS}

O IBM-SPSS versão 20.0 foi utilizado para análise dos dados. Os gráficos de Bland-Altman foram calculados e plotados com o software $R$, versão 3.1.2 ( $R$ Foundation for Statistical Computing, Viena, Áustria - http://www.r-project.org) usando rotinas propostas por Hirakata e Camey (2009). A população estudada e as características clínicas foram definidas utilizando estatística descritiva.

Valores outliers foram removidos utilizando o método para a detecção de outlier proposto por Leys et al. (2013), que considera a mediana mais ou menos 2,5 vezes o desvio absoluto mediano.

O desempenho no Bassin e Bridge foram calculados usando blocos (média de cinco tentativas cada) para todas as fases do estudo (quatro blocos durante a aquisição, um bloco na retenção e um bloco na transferência). Estes blocos foram apresentados como médias e desvios-padrão. Para cada bloco de cinco tentativas, o erro absoluto $(E A)$, erro constante $(E C)$ e erro variável $(E V)$ foram calculados utilizando as fórmulas descritas por de Mello Monteiro et al (2017).

As análises para consistência interna, confiabilidade e validade concorrente foram realizadas em todos os blocos (Bl1, BI2, Bl3, Bl4, R e T) e erros calculados ( $E A$, $E C, E V$ ), tanto para o Bridge quanto para o Bassin em ambos os grupos (DMD e DT).

A consistência interna foi obtida pelo alfa de Cronbach, sendo que, para os valores entre 0,7 a 0,8 ela foi considerada como satisfatória, e acima de 0,8 como desejável (ALTMAN e BLAND, 1997).

A análise da confiabilidade foi expressa usando o coeficiente de correlação intraclasse (CCls) do tipo (2, k) e seus respectivos intervalos de confiança (IC) de $95 \%$.

A validação concorrente foi expressa pelos níveis de concordância entre Bridge e Bassin representada pelos CCls do tipo (2, k) e seus respectivos IC de $95 \%$, bem como pelo coeficiente de correlação de Pearson.

Além disso, as parcelas de Bland-Altman foram geradas para fornecer uma representação visual da diferença entre o Bridge e o Bassin, que nos permitem comparar os dois métodos de medição do tempo de execução na tarefa de timing coincidente. Para isso, uma linha contínua central representa a diferença média entre os dois métodos (ou viés) e um intervalo de confiança, entre os quais se espera que 95\% das diferenças entre uma técnica de medição e outra sejam incluídas, representadas como limite superior e limite inferior. 
O coeficiente de correlação intraclasse $(\mathrm{CCl})$ com valor inferior a 0,5 foi indicativo de baixa confiabilidade, enquanto valores entre 0,5 e 0,75 indicaram confiabilidade moderada; valores entre 0,75 e 0,9 indicaram boa confiabilidade, e valores maiores que 0,90 indicaram excelente confiabilidade (KOO e LI, 2016).

A significância estatística foi definida em $p<0,05$. 


\section{RESULTADOS}

Não houve diferença significativa entre os grupos quanto à idade para distrofia muscular de Duchenne (DMD), com média 14,72 (DP=2,28) e desenvolvimento típico (DT), com média de 13,78 (DP=2,98), com $p=0,23$.

As médias, a consistência interna e os coeficientes de correlação intraclasse da confiabilidade das pontuações das tarefas de Timing Coincidente (TTC) em cada bloco dos erros absoluto, constante e variável (EA, EC e EV, respectivamente) são apresentados na Tabela 2. Quando considerados em conjunto (BI1, BI2, BI3, BI4, R e $\mathrm{T})$, Bridge e Bassin mostraram aceitáveis consistências internas para os blocos, variando de $\alpha=0,75$ a $\alpha=0,84$ para Bridge e $\alpha=0,74$ para $\alpha=0,89$ para Bassin. $O$ grupo DT teve maior consistência interna nos blocos EA e EC $(\alpha=.89)$ quando comparado ao grupo DMD (com $\alpha=.84$ e $\alpha=.81$, respectivamente). A consistência interna das pontuações do bloco de transferência mostrou os escores mais baixos em ambas as tarefas, com $\alpha=0,75$ para Bridge e $\alpha=0,74$ para Bassin.

Tabela 2 - Média, desvio padrão, consistência interna, e validade concorrente dos blocos para as tarefas de timing coincidente em ambos os instrumentos, apresentados por grupo e erros.

\begin{tabular}{|c|c|c|c|c|c|c|}
\hline & \multicolumn{3}{|c|}{ Grupo de distrofia muscular de Duchenne } & \multicolumn{3}{|c|}{ Grupo de Desenvolvimento Típico } \\
\hline & EA & EC & EV & EA & EC & EV \\
\hline \multicolumn{7}{|c|}{ Jogo Timing Coincidente do pacote de jogos do Team Bridge games (Bridge) } \\
\hline Bl1 & $300,95 \pm 117,13$ & $299,89 \pm 115,49$ & $100,08 \pm 132,50$ & $444,31 \pm 363,07$ & $427,43 \pm 348,63$ & $133,70 \pm 207,40$ \\
\hline BI2 & $317,84 \pm 207,85$ & $316,34 \pm 209,57$ & $97,54 \pm 95,60$ & $453,05 \pm 393,83$ & $413,12 \pm 387,37$ & $131,30 \pm 281,45$ \\
\hline $\mathrm{BI3}$ & $307,37 \pm 114,43$ & $306,43 \pm 111,47$ & $100,22 \pm 109,14$ & $431,39 \pm 351,07$ & $425,67 \pm 356,52$ & $127,31 \pm 161,93$ \\
\hline BI4 & $366,50 \pm 256,18$ & $366,50 \pm 256,18$ & $80,57 \pm 56,12$ & $454,75 \pm 385,25$ & $452,85 \pm 385,48$ & $105,68+151,56$ \\
\hline $\mathbf{R}$ & $321,48 \pm 151,36$ & $312,08 \pm 133,00$ & $112,12 \pm 121,76$ & $370,13 \pm 293,93$ & $366,91 \pm 297,26$ & $77,54 \pm 91,86$ \\
\hline $\mathbf{T}$ & $225,85 \pm 146,60$ & $208,92 \pm 138,19$ & $70,23 \pm 54,16$ & $264,31 \pm 294,67$ & $190,18 \pm 217,90$ & $132,53 \pm 307,44$ \\
\hline k & 6 & 6 & 6 & 6 & 6 & 6 \\
\hline$\alpha$ & 0,97 & 0,96 & 0,85 & 0,93 & 0,93 & 0,80 \\
\hline $\mathrm{CCl}_{2, \mathrm{k}}$ & 0,97 & 0,96 & 0,85 & 0,92 & 0,92 & 0,80 \\
\hline $95 \% \mathrm{Cl}$ & $0,94-0,98$ & $0,93-0,98$ & $0,74-0,92$ & $0,89-0,95$ & $0,87-0,95$ & $0,71-0,87$ \\
\hline \multicolumn{7}{|c|}{ Bassin Anticipation Timer (Bassin) } \\
\hline Bl1 & $86,28 \pm 82,80$ & $76,53 \pm 87,29$ & $39,62 \pm 25,47$ & $101,65+73,84$ & $92,75 \pm 75,63$ & $43,44 \pm 34,53$ \\
\hline $\mathrm{BI} 2$ & $83,87 \pm 70,25$ & $70,67 \pm 81,09$ & $45,69 \pm 27,87$ & $88,36 \pm 60,15$ & $76,28 \pm 66,84$ & $47,21 \pm 29,11$ \\
\hline $\mathrm{BI3}$ & $92,50 \pm 57,91$ & $72,12 \pm 73,69$ & $45,36 \pm 36,62$ & $92,23 \pm 62,41$ & $81,83 \pm 68,36$ & $40,45 \pm 27,78$ \\
\hline BI4 & $93,10 \pm 74,05$ & $77,17 \pm 78,40$ & $52,82 \pm 48,77$ & $98,14 \pm 64,35$ & $84,29 \pm 74,04$ & $48,22 \pm 27,78$ \\
\hline
\end{tabular}




\begin{tabular}{|c|c|c|c|c|c|c|}
\hline $\mathbf{R}$ & $88,88 \pm 60,78$ & $85,50 \pm 63,56$ & $33,80 \pm 24,08$ & $98,69+49,38$ & $90,49 \pm 56,12$ & $35,76 \pm 32,01$ \\
\hline $\mathbf{T}$ & $120,04 \pm 46,16$ & $106,43 \pm 53,86$ & $44,67 \pm 26,63$ & $122,93 \pm 98,96$ & $100,13 \pm 78,91$ & $41,18+27,03$ \\
\hline k & 6 & 6 & 6 & 6 & 6 & 6 \\
\hline$\alpha$ & 0,91 & 0,91 & 0,67 & 0,92 & 0,93 & 0,72 \\
\hline $\mathrm{ICC}_{2, \mathrm{k}}$ & 0,91 & 0,90 & 0,66 & 0,91 & 0,93 & 0,72 \\
\hline $95 \% \mathrm{Cl}$ & $0,84-0,95$ & $0,83-0,95$ & $0,43-0,82$ & $0,87-0,94$ & $0,90-0,96$ & $0,59-0,81$ \\
\hline \multicolumn{7}{|c|}{ Bridge + Bassin } \\
\hline k & 12 & 12 & 12 & 12 & 12 & 12 \\
\hline$\alpha$ & 0,84 & 0,81 & 0,75 & 0,89 & 0,89 & 0,74 \\
\hline $\mathrm{ICC}_{2, \mathrm{k}}$ & 0,74 & 0,66 & 0,72 & 0,82 & 0,82 & 0,73 \\
\hline $95 \% \mathrm{Cl}$ & $0,52-0,85$ & $0,45-0,82$ & $0,54-0,85$ & $0,72-0,89$ & $0,71-0,89$ & $0,61-0,82$ \\
\hline
\end{tabular}

Nota: Bl1: Primeiro bloco com cinco repetições; BI2: Segundo bloco com cinco repetições; BI3: Terceiro bloco com cinco repetições; Bl4: Quarto bloco com cinco repetições; R: Bloco de retenção com cinco repetições; T: Bloco de transferência com cinco repetições; EA: Erro absoluto; EC: Erro constante; EV: Erro variável; $\alpha$, Alfa de Crombach; $\mathrm{CCl}_{2}$, k: Coeficiente de Correlação intraclasse; IC: Intervalo de confiança.

Foi calculado o coeficiente de correlação intraclasse $(\mathrm{CCl})$ entre os tempos obtidos nos seis blocos para examinar a validade convergente entre a tarefa de Timing Coincidente no Bridge e Bassin. Com exceção do EC, o CCl mostrou uma excelente confiabilidade entre Bridge e Bassin com valores variando de 0,66 a 0,74 no grupo DMD e 0,73 a 0,82 no grupo DT (Tabela 2).

Tabela 3 - Correlações de Pearson entre os resultados dos blocos do Timing Coincidente do Bridge e Bassin em três erros, divididos por grupo de participantes

\begin{tabular}{lllllll}
\hline & DMD & & & DT & \\
& EA & EC & EV & EA & EC & EV \\
\hline BI1 & $0,48^{* *}$ & 0,17 & $-0,23$ & $0,43^{* *}$ & $0,38^{* *}$ & 0,02 \\
B12 & $-0,07$ & $-0,24$ & $-0,31$ & $0,48^{* *}$ & $0,45^{* *}$ & 0,07 \\
B13 & $0,74^{* *}$ & $0,58^{* *}$ & $-0,18$ & $0,39^{* *}$ & $0,38^{* *}$ & 0,05 \\
BI4 & $0,39^{*}$ & $0,37^{* *}$ & 0,01 & $0,50^{\star *}$ & $0,45^{* *}$ & 0,08 \\
R & 0,19 & 0,14 & $-0,09$ & $0,55^{\star *}$ & $0,49^{* *}$ & 0,08 \\
T & $-0,08$ & 0,03 & $-0,15$ & 0,23 & 0,16 & $-0,11$
\end{tabular}

Nota: B11: Primeiro bloco com cinco repetições; BI2: Segundo bloco com cinco repetições; BI3: Terceiro bloco com cinco repetições; B14: Quarto bloco com cinco repetições; R: Bloco de retenção com cinco repetições; T: Bloco de transferência com cinco repetições EA: Erro absoluto; EC: Erro constante; EV: Erro variável *: Valor de $p<.05 ;{ }^{* *}$ : Valor de $p<.001$. 
Os resultados da correlação entre o Bridge e o Bassin para os três tipos de erro (erro absoluto, erro constante e erro variável) são relatados na Tabela 3. Com exceção do bloco de transferência e no EV, a correlação de Pearson mostrou excelente correlação entre blocos para o grupo DT. O grupo DMD apresentou excelente correlação nos blocos Bl3 e Bl4 em EA e EC, e sem correlação em todos os blocos do EV.

As figuras 4, 5 e 6 apresentam os gráficos de Bland-Altman para todos os blocos de medição, para os erros absoluto, constante e variável, respectivamente.

Figura 4 - Gráficos e Bland-Altman para as tarefas de timing coincidente do Bridge e Bassin representados para erro absoluto.

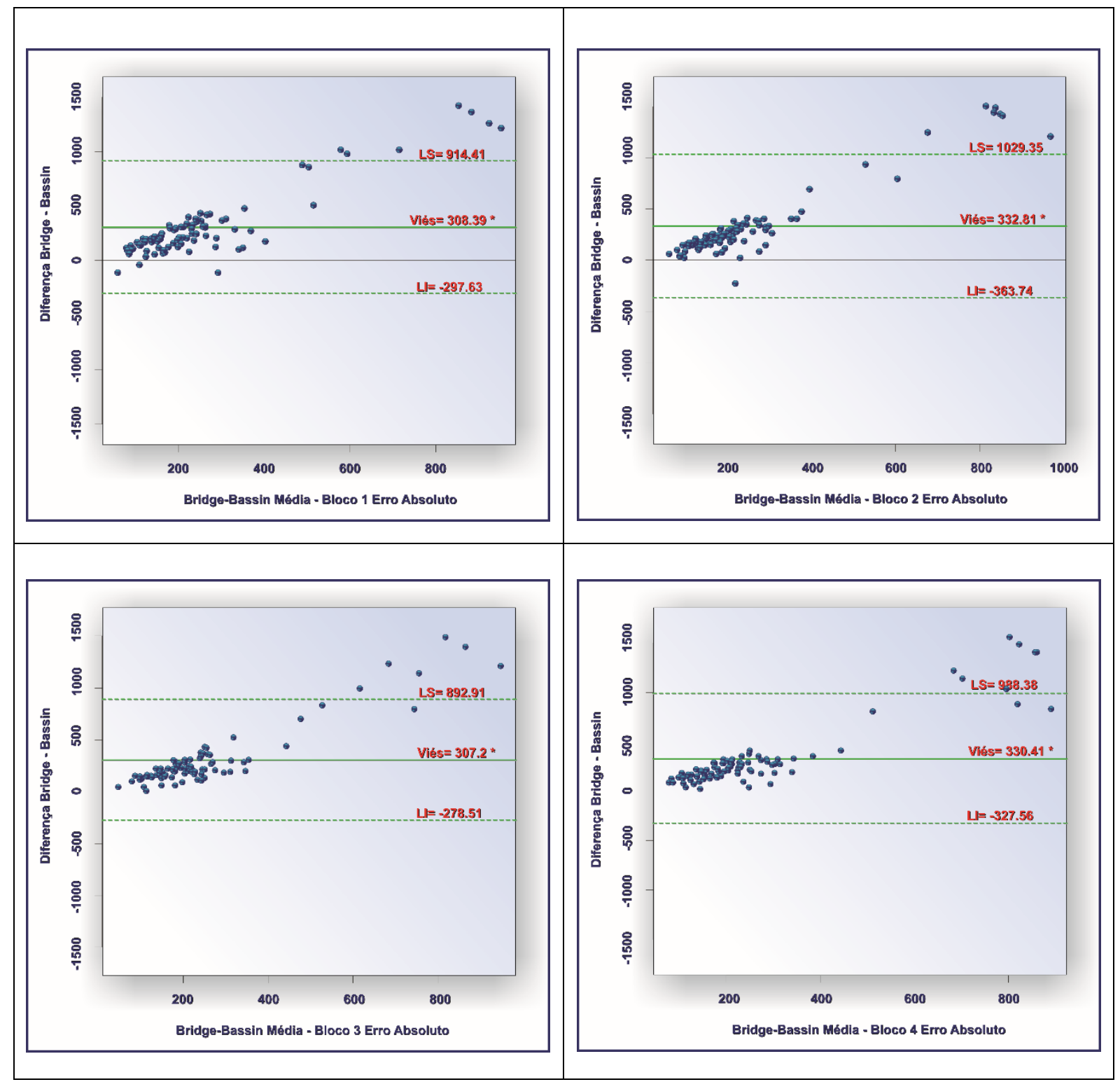




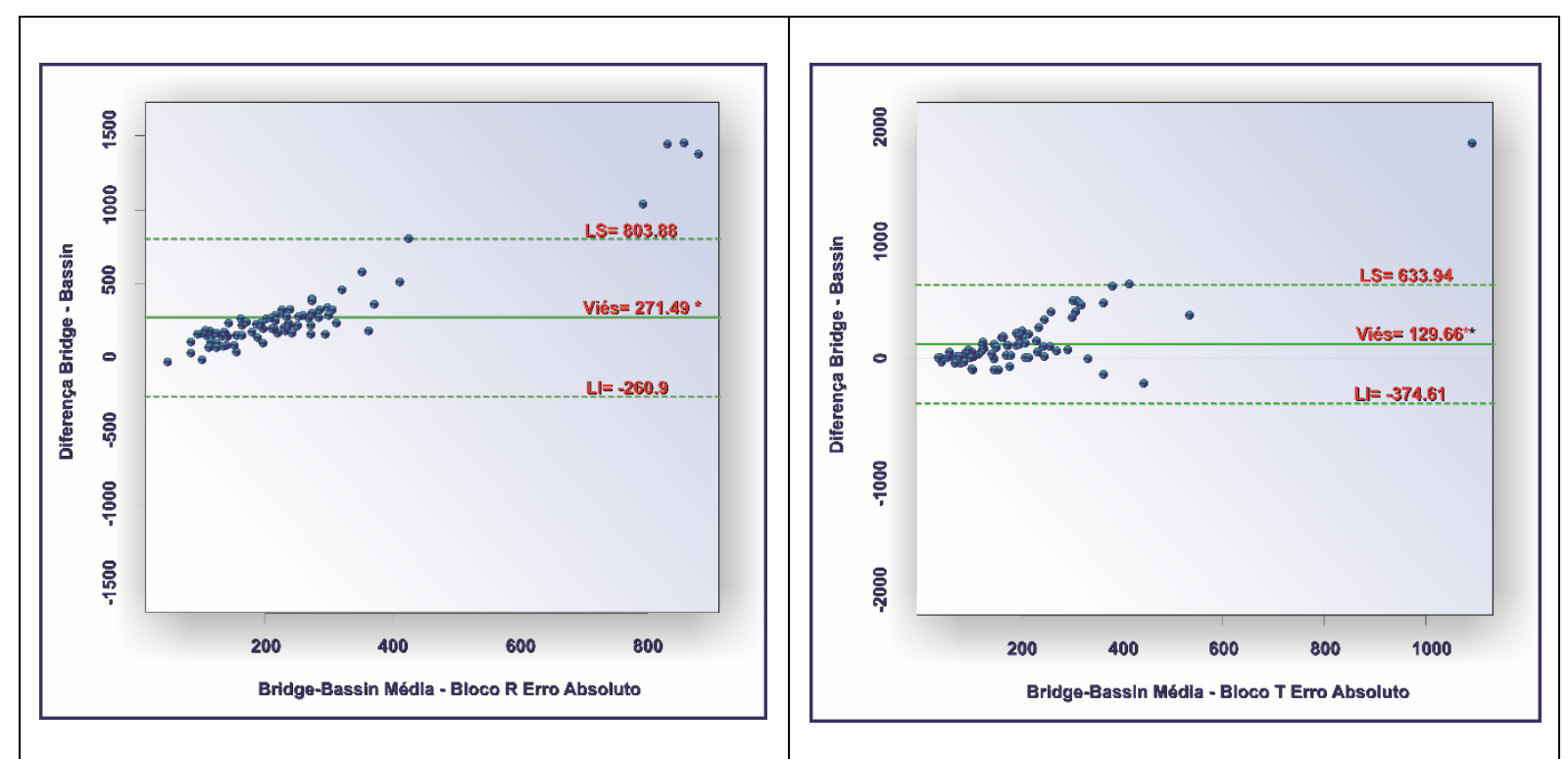

Legenda: LS - Limite Superior, LI - Limite Inferior, Bloco R - Bloco de retenção, Bloco T - Bloco de transferência.

Fonte: Do próprio autor.

Considerando o erro absoluto que não leva em conta a direção de cada resposta até o alvo, observa-se que em geral, os limites de concordância entre as pontuações dos blocos Bridge e Bassin foram amplos (Figura 4), com viés significativo para todos os blocos. No entanto, o bloco de transferência, com aumento da velocidade apresentou os indicativos mais baixos.

Figura 5 - Gráficos e Bland-Altman para as tarefas de timing coincidente do Bridge e Bassin representados para erro constante.

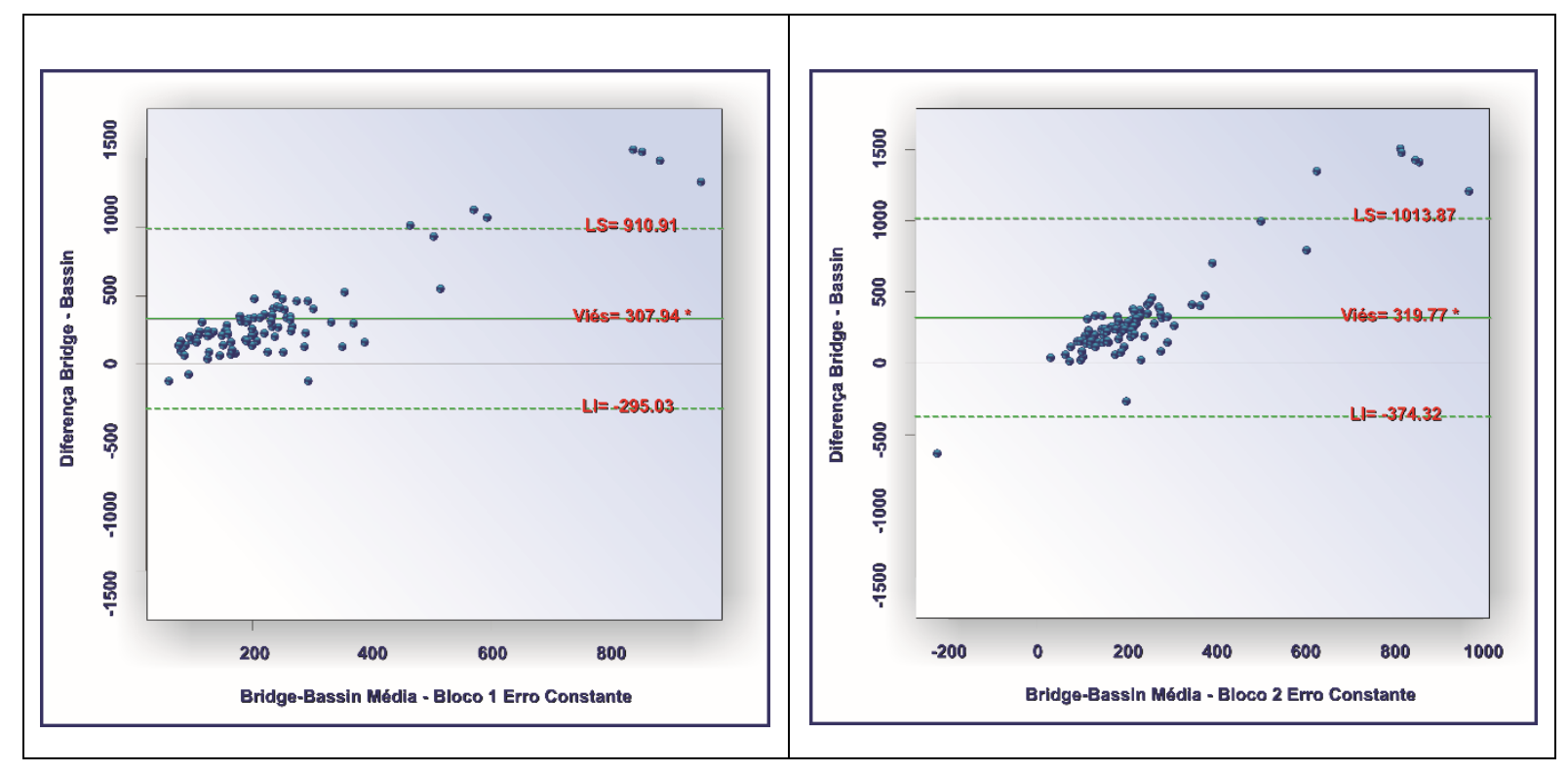




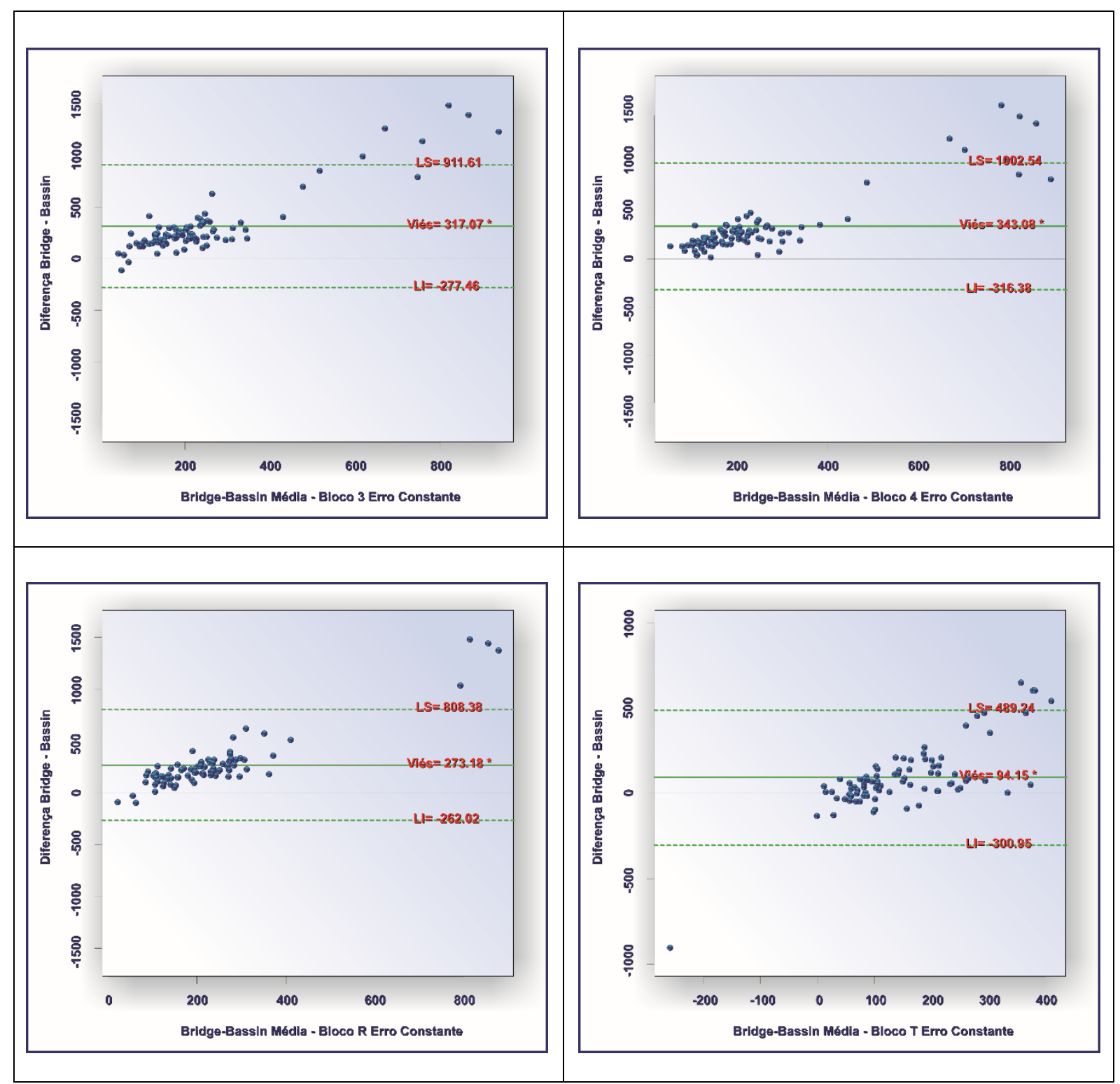

Legenda: LS - Limite Superior, LI - Limite Inferior, Bloco R - Bloco de retenção, Bloco T - Bloco de transferência.

Fonte: Do próprio autor.

Para o erro constante, que leva em conta a direção do erro (se negativo ou positivo) representando a antecipação ou atraso, o viés entre os métodos ficou acima de 300 unidades, com viés significativo para todos os blocos (Figura 6). 
Figura 6 - Gráficos e Bland-Altman para as tarefas de timing coincidente do Bridge e Bassin representados para erro variável.

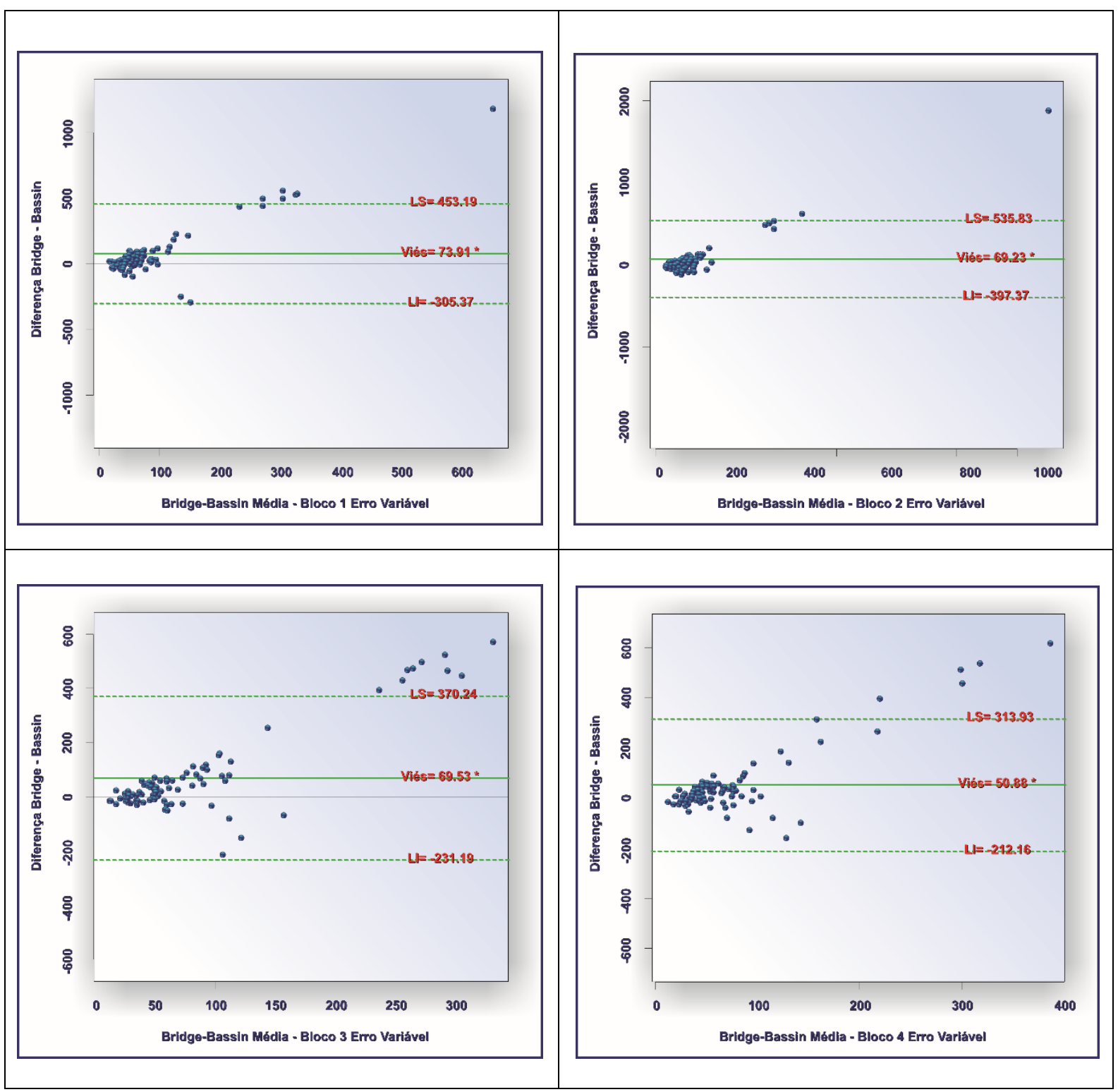




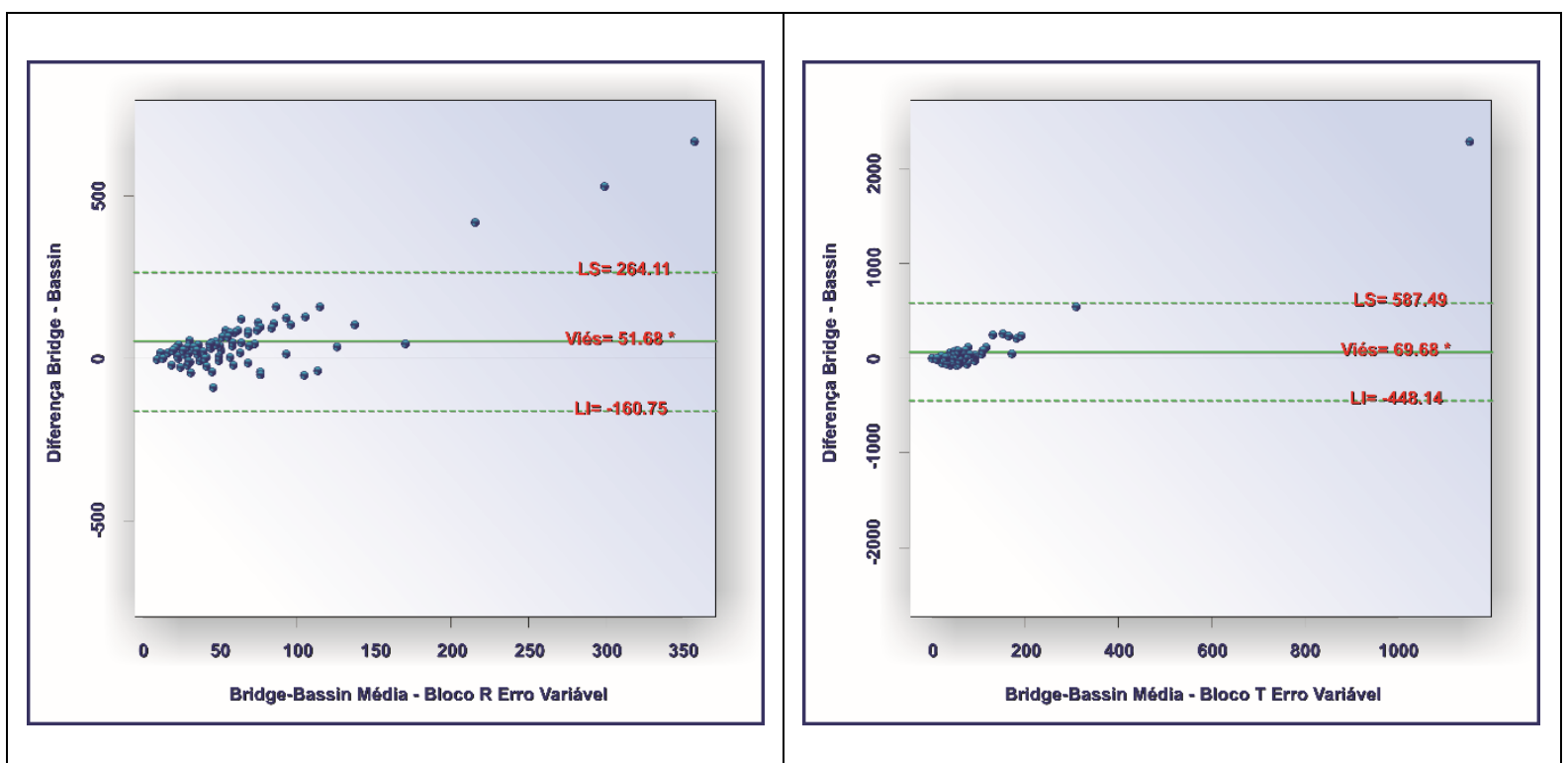

Legenda: LS - Limite Superior, LI - Limite Inferior, Bloco R - Bloco de retenção, Bloco T - Bloco de transferência.

Fonte: Do próprio autor.

O gráfico de Bland-Altman para o erro variável apresentou o menor viés para todos os blocos, apesar de ainda significativo (Figura 6). 


\section{DISCUSSÃO}

Neste estudo, a validação de um software de realidade virtual não imersiva para fornecer a avaliação do desempenho em uma tarefa de timing coincidente foi realizada usando participantes com diagnóstico de distrofia muscular de Duchenne (DMD) e indivíduos saudáveis como grupo controle. A confirmação da validade, com a análise da confiabilidade e consistência interna de um novo jogo de realidade virtual (RV) como tecnologia Assistiva para pessoas com DMD pode oferecer aos profissionais de reabilitação a possibilidade de medir dificuldades no controle motor e na aprendizagem nesta população.

Os principais achados deste estudo foram a consistência interna satisfatória e excelente confiabilidade, confirmada pelos valores do coeficiente de correlação intraclasse $(\mathrm{CCl})$ e os limites de concordância nas parcelas de Bland-Altman em praticamente todos os erros calculados. Para que um instrumento de avaliação seja confiável, os resultados obtidos devem ser consistentes, realistas e reprodutíveis em condições semelhantes.

Os resultados do estudo sugerem que o jogo Timing Coincidente do Team Bridge Games (Bridge) e o Bassin Antecipation Timer (Bassin) realmente medem um constructo semelhante apresentado pela validade concorrente de ambos os testes, com valores de $\mathrm{CCl} \geq 0,66$. O alfa de Cronbach acima de 0,74 , reforça a homogeneidade ou correlações adequadas dos itens e a consistência de que ambos os testes medem a mesma dimensão ou o construto teórico (MAROCO e GARCIA-MARQUES, 2006). Com relação às medições feitas usando a tarefa TTC no Bridge e Bassin, os resultados de confiabilidade são consistentes com pesquisas anteriores que relataram bons valores de $\mathrm{CCl}$ ao utilizar procedimentos de medição similares (KOLBER et al., 2013).

As correlações sugerem uma relação entre o Bridge e os escores da avaliação do Bassin, isto significa que o coeficiente de correlação está longe de 0 . Essas correlações demonstram o valor potencial do jogo Bridge na avaliação clínica da tarefa TTC. Na validação desta tarefa usando um protocolo semelhante em adultos saudáveis, os autores reportam que a validade concorrente foi de fraca a boa para a medidas dos blocos em todas as variáveis quando estes foram comparados usando o coeficiente de correlação intraclasse ( $\mathrm{CCl}$ ); suficiente quando comparados usando o alfa de Cronbach, e bom a excelente quando comparados usando o coeficiente de correlação de Pearson (CROCETTA et al., 2019). 
As correlações entre um novo teste e o padrão-ouro observado neste estudo são semelhantes aos resultados observados em outras pesquisas. Tong et al. (2016) propuseram o uso de jogos sérios para rastrear o status cognitivo anormal em situações em que pode ser muito caro ou impraticável usar avaliações cognitivas padrão. Eles demonstraram que o desempenho no jogo sério se correlacionava significativamente com as ferramentas padrão. Jalink et al. (2014) encontraram uma correlação significativamente alta entre um novo simulador baseado em videogames e um teste de instrumento já estabelecido, indicando uma sólida validade concorrente.

Ao analisar a confiabilidade, consistência interna e validade de um novo teste em pessoas com distrofia muscular, Artilheiro et al (2018) utilizaram o coeficiente de correlação intraclasse, o alfa de Cronbach e a correlação de Spearman e reportam uma boa consistência interna e fortes correlações entre o novo teste e um teste já validado.

Cabe ressaltar que no Bassin os participantes apresentaram menores escores (melhor desempenho) quando comparado ao Bridge. Entretanto, não houve erro sistemático na técnica estatística aplicada que pudesse explicar as diferenças, como também reportado por Kolber et al. (2013). Em dois estudos utilizando as mesmas tarefas aqui apresentadas, o Bassin apresentou escores mais baixos (BEZERRA et al, 2017; CROCETTA et al, 2019). Podemos supor que essa diferença pode ser devido aos fatores discutidos a seguir

Primeiro, as variações consideráveis nos métodos de interação em que os usuários usaram o polegar para pressionar um botão em vez de um dedo indicador / médio para interagir com o teclado do computador. A influência de padrões de movimento na função motora é uma temática importante para ser verificada. Provavelmente o Bassin necessite de um movimento mais específico (o participante segura o botão acionador ao mesmo tempo em que deve pressionar o botão do dispositivo) quando comparado ao Bridge (o participante mantém a mão apoiada sobre a mesa e deve pressionar a barra de espaço do teclado do computador). Desta forma a utilização de movimentos mais proximais e globais (que requerem coordenação, aceleração e desaceleração de movimentos) dificultaram a tarefa e podem ser responsáveis pelo pior desempenho no Bridge. Por outro lado, podemos especular que a tarefa no Bassin necessite de maior precisão com movimentos finos o que facilitou a execução. 
Segundo, o Bridge é composto de bolhas dispostas na vertical na tela do computador (mais abstratas) e o Bassin apresenta luzes de LED dispostas na horizontal (mais reais). Este fator de diferença de ambientes é importante na prática de uma tarefa, ou seja, para a verificação do contexto da tarefa. Segundo Larsson, Sandberg e Smith (2009) o contexto em que a ação é assumida influencia o processo de aprendizagem e a oportunidade da pessoa em desenvolver estratégias de ação. $A$ ação requer interpretação e criatividade, mas nem sempre é explícita ou mesmo consciente. Provavelmente para o grupo que praticou a tarefa com o Bassin com uma representação concreta do objeto, teve melhor desempenho. Uma tarefa que envolve uma interação direta com o objeto, sem a representação virtual da tarefa junto com o contato físico facilitado pelo dispositivo distal (tarefa mais real) auxiliou na execução do Bassin. No entanto, ao realizar uma tarefa em 3D (virtual) existe uma organização espaço-temporal diferente do ambiente real. Por exemplo, Van Der Weel, Van Der Meer e Lee (1991) e de Mello Monteiro et al. (2014 e 2017) compararam o desempenho de pessoas com alteração da postura e movimento e grupo controle (formado com pessoas com desenvolvimento típico) e verificaram que em tarefas com ambiente 3D (mais virtual) ambos os grupos apresentaram maior dificuldade. Provavelmente o Bassin reproduziu uma tarefa mais real com luzes (LED) acendendo e apagando diferente das bolhas virtuais do Bridge o que pode ter dificultado a tarefa.

Um terceiro motivo pode ser explicado pela dificuldade em medir o tempo em um computador que envolve um sistema operacional multitarefa, como o Windows (CROCETTA e ANDRADE, 2015). O Bassin é um aparelho dedicado, com hardware projetado para funcionar exclusivamente para controlar os LEDs e o tempo, sem a interferência de outros pedidos para dividir sua "atenção" com outro sistema, como é o caso do Windows. Por outro lado, o Bridge é um programa de computador, e depende da resolução do temporizador e da velocidade do computador (BILSKI e WINIECKI, 2012). Crocetta et al. (2014) na validação de um novo software para medir o tempo de reação e comparado a um software com hardware dedicado para a mesma tarefa, utilizaram um robô externo para avaliar os recursos computacionais utilizados (sistema operacional, programação de software, computador, teclado e monitor) para explicar a diferença encontrada nos dois testes propostos.

Por outro lado, os valores de a e $\mathrm{CCl}$ no Bridge foram superiores aos encontrados no Bassin, sugerindo que os participantes foram mais precisos no Bridge. Isso pode ser observado pelos menores coeficientes encontrados para o erro variável 
no Bassin, uma vez que este indicador se refere a precisão. Isso aconteceu tanto para o grupo DMD quanto para o grupo DT, confirmando a validade do Bridge. O valor mínimo aceitável para considerar um instrumento confiável é de 0,7. Valores acima promovem maior robustez à pesquisa em saúde (STREINER, 2003), resultados semelhantes encontrados em nosso estudo.

$\mathrm{Na}$ Tabela 3 observamos que a correlação foi mais forte para os últimos blocos, em face disso podemos dizer que essa correlação pode ter sido decorrente da familiarização com a tarefa, e isso ficou mais evidente no bloco de retenção. Essa tendência pode ser visualizada nos gráficos de Bland-Altman, onde é possível observar que os blocos de 1 a 4 apresentam uma maior dispersão de pontos, uma vez que o bloco de retenção possui o menor viés e os menores limites de concordância.

Além disso, foi possível observar uma aceitação geral do jogo do Bridge, apesar do interesse em aparelhos como o Bassin. O grupo DMD expressou sua satisfação em realizar a tarefa de timing coincidente com êxito e estava mais interessado em saber a possibilidade de usar a tarefa com outras interfaces, como Kinect ou Leap Motion. O uso de diferentes interfaces de interação com o jogo pode ser relevante para identificar quais pacientes podem se beneficiar desta característica.

Ao lidar com indivíduos com DMD, temos questões importantes a considerar, o que pode interferir diretamente com a execução da tarefa. Entre as formas de observar o desempenho na execução das tarefas, podemos aplicar conceitos de aprendizagem motora, e neste estudo, tanto na tarefa do Bassin como na tarefa do Bridge, foi utilizado esse princípio, realizando a tarefa em fases - aquisição (20 repetições), retenção (5 repetições) e transferência (5 repetições). Assim como neste estudo, outros utilizaram essa forma de avaliação com essa população (MALHEIROS et al., 2016; CAPELINI, C. M. et al., 2017; QUADRADO et al., 2017).

O principal interesse é saber se a informação oferecida pelo Timing coincidente virtual é confiável, válida e constante para permitir seu uso em ambientes de pesquisa ou treinamento clínico. A possibilidade de validar e verificar a confiabilidade de uma tarefa de timing coincidente em um ambiente virtual propicia o uso da avaliação para o desenvolvimento de protocolos de pesquisa e reabilitação na DMD.

As principais conclusões deste estudo são a consistência interna satisfatória e a excelente confiabilidade, confirmada pelos valores do coeficiente de correlação intraclasse em praticamente todos os erros calculados. 
Os resultados sugerem que a avaliação da tarefa de Timing coincidente usada pelo "Team Bridge" tem confiabilidade confirmada no desempenho em pacientes com DMD. A simplicidade do uso de um computador permite a autoadministração da avaliação do Timing Coincidente pelos profissionais que estão diretamente envolvidos com a atenção a essa população.

Apesar dos resultados positivos na validade e confiabilidade do Bridge, algumas limitações devem ser apresentadas: (1) a grande variabilidade dos padrões dos indivíduos com DMD, como já observado em outros estudos com essa população (HUKUDA et al., 2013); (2) dificuldade em homogeneizar a amostra devido à ampla variação, assim usamos uma amostra de conveniência; (3) os menores escores apresentados no Bassin quando comparados ao Bridge apresentaram algumas hipóteses, mas devem ser considerados como uma limitação. 


\section{CONCLUSÃO}

O jogo de Timing Coincidente do "Team Bridge Games" é uma opção válida de software com realidade virtual como tecnologia assistiva para a mensuração deste tipo de tarefa em indivíduos com DMD. Este estudo reforça a importância do desenvolvimento de ferramentas que sejam válidas e confiáveis e permitam recorrer às inovações tecnológicas como a dos ambientes virtuais. 


\section{REFERÊNCIAS}

AK, E.; KOCAK, S. Coincidence-anticipation timing and reaction time in youth tennis and table tennis players. Perceptual and Motor Skills, v. 110, n. 3, p. 879-887, Jun 2010. ISSN 0031-5125.

AKPINAR, S.; DEVRILMEZ, E.; KIRAZCI, S. Coincidence-anticipation timing requirements are different in racket sports. Perceptual and Motor Skills, v. 115, n. 2, p. 581-593, Oct 2012. ISSN 0031-5125.

AN, C. M.; PARK, Y. H. The effects of semi-immersive virtual reality therapy on standing balance and upright mobility function in individuals with chronic incomplete spinal cord injury: A preliminary study. J Spinal Cord Med, v. 41, n. 2, p. 223-229, Mar 2018. ISSN 1079-0268.

ANTUNES, T. P. C. et al. Computer classes and games in virtual reality environment to reduce loneliness among students of an elderly reference center Study protocol for a randomised cross-over design. Medicine, v. 96, n. 10, Mar 2017. ISSN 0025-7974.

ARANE, K.; BEHBOUDI, A.; GOLDMAN, R. D. Virtual reality for pain and anxiety management in children. Can Fam Physician, v. 63, n. 12, p. 932-934, Dec 2017. ISSN 0008-350x.

ARTILHEIRO, M. C. et al. Reliability, validity and description of timed performance of the Jebsen-Taylor Test in patients with muscular dystrophies. Brazilian Journal of Physical Therapy, v. 22, n. 3, p. 190-197, May-Jun 2018. ISSN 1413-3555.

BAMER, A. M. et al. Frequency of purchase and associated costs of assistive technology for Washington State Medicaid program enrollees with spina bifida by age. Disabil Health J, v. 3, n. 3, p. 155-61, Jul 2010. ISSN 1876-7583.

BELISLE, J. J. Accuracy, reliability, and refractoriness in a coincidence-anticipation task. Research Quarterly. American Association for Health, Physical Education and Recreation, v. 34, n. 3, p. 271-281, 1963. ISSN 1067-1188. 
BELLO, L. et al. Cardiomyopathy in patients with POMT1-related congenital and limb-girdle muscular dystrophy. Eur J Hum Genet, v. 20, n. 12, p. 1234-9, Dec 2012. ISSN 1018-4813.

BERARD, C. et al. A motor function measure for neuromuscular diseases. Construction and validation study. Neuromuscul Disord, v. 15, n. 7, p. 463-70, Jul 2005. ISSN 0960-8966 (Print) 0960-8966.

BEZERRA, I. M. P. et al. Functional performance comparison between real and virtual tasks in older adults A cross-sectional study. Medicine, v. 97, n. 4, Jan 2018. ISSN 0025-7974.

BIDDIX, J. Research rundowns: Uncomplicated reviews of educational research methods 2009.

BILSKI, P.; WINIECKI, W. Methods of assessing the time efficiency in the virtual measurement systems. Computer Standards \& Interfaces, v. 34, n. 6, p. 485-492, 2012. ISSN 0920-5489.

BIRNKRANT, D. J. et al. Diagnosis and management of Duchenne muscular dystrophy, part 1: diagnosis, and neuromuscular, rehabilitation, endocrine, and gastrointestinal and nutritional management. Lancet Neurol, v. 17, n. 3, p. 251-267, Mar 2018. ISSN 1474-4422.

BLAND, J. M.; ALTMAN, D. G. Statistics notes: Cronbach's alpha. BMJ, v. 314, n. 7080, p. 572, 1997. ISSN 0959-813809598138.

BRYANT, L.; BRUNNER, M.; HEMSLEY, B. A review of virtual reality technologies in the field of communication disability: implications for practice and research. Disabil Rehabil Assist Technol, p. 1-8, Jan 13 2019. ISSN 1748-3107.

BURDEA, G. C. et al. Robotics and gaming to improve ankle strength, motor control, and function in children with cerebral palsy--a case study series. IEEE Trans Neural Syst Rehabil Eng, v. 21, n. 2, p. 165-73, Mar 2013. ISSN 1534-4320. 
BUSHBY, K. et al. Diagnosis and management of Duchenne muscular dystrophy, part 1: diagnosis, and pharmacological and psychosocial management. Lancet Neurol, v. 9, n. 1, p. 77-93, Jan 2010. ISSN 1474-4422.

CAPELINI, A. M. et al. Improvements in motor tasks through the use of smartphone technology for individuals with Duchenne muscular dystrophy. Neuropsychiatric Disease and Treatment, v. 13, p. 2209-2217, 2017. ISSN 1178-2021.

COOK, A.; HUSSEY, S. Assistive Technologies: Principles and Practices. St. Louis, Missouri, EUA. Mosby-Year Book: Inc 1995.

COYNE, C. Video" games" in the clinic: PTs report early results. PT: Magazine of Physical Therapy, v. 16, n. 5, 2008.

CRABTREE, D. A.; ANTRIM, L. R. Reconsideration of measurement of error in human motor learning. Perceptual and Motor Skills, v. 67, n. 2, p. 568-570, Oct 1988. ISSN 0031-5125.

CROCETTA, T. B.; ANDRADE, A. Retrasos en la medición del tiempo con el uso de computadoras en la investigación del Tiempo de Reacción. Revista de psicología del deporte, v. 24, n. 2, p. 0341-349, 2015.

CROCETTA, T. B. et al. Virtual reality software package for implementing motor learning and rehabilitation experiments. Virtual Reality, p. 1-11, 2017. ISSN 13594338.

. Concurrent Validity and Reliability of Alternative Computer Game for the Coincidence-Anticipation Timing Task. Measurement in Physical Education and Exercise Science, p. 1-17, 2019. ISSN 1091-367X. . Validity of software for measurement of Total Reaction Time with simple stimulus-TRT_S 2012. Journal of Human Growth and Development, v. 24, n. 3, p. 295-303, 2014. ISSN 2175-3598. 
DA SILVA, T. D. et al. Realidade virtual na paralisia cerebral. Definição, tipos e possibilidades de intervenção. PARALISIA CEREBRAL, v. 1, p. 249, 2015.

DARRAS, B. T. et al. Neuromuscular disorders of infancy, childhood, and adolescence: a clinician's approach. Elsevier, 2014. ISBN 0124171273.

DE CARVALHO, E. V. et al. Development and Reliability of the Functional Evaluation Scale for Duchenne Muscular Dystrophy, Gait Domain: A Pilot Study. Physiother Res Int, v. 20, n. 3, p. 135-46, Sep 2015. ISSN 1358-2267.

DE FREITAS, B. L. et al. Analysis of Different Device Interactions in a Virtual Reality Task in Individuals With Duchenne Muscular Dystrophy-A Randomized Controlled Trial. Front Neurol, v. 10, p. 24, 2019. ISSN 1664-2295 (Print) 1664-2295.

DE MELLO MONTEIRO, C. B. et al. Short-term motor learning through nonimmersive virtual reality task in individuals with down syndrome. BMC Neurol, v. 17, n. 1, p. 71, Apr 14 2017. ISSN 1471-2377.

. Transfer of motor learning from virtual to natural environments in individuals with cerebral palsy. Res Dev Disabil, v. 35, n. 10, p. 2430-7, Oct 2014. ISSN 08914222.

DE SANTANA, C. M. F. et al. Efeitos do tratamento com realidade virtual não imersiva na qualidade de vida de indivíduos com Parkinson. Revista Brasileira de Geriatria e Gerontologia, v. 18, n. 1, p. 49-58, 2015. ISSN 1809-9823.

DEMAIN, S. et al. Assistive technologies after stroke: self-management or fending for yourself? A focus group study. BMC Health Serv Res, v. 13, p. 334, Aug 222013. ISSN 1472-6963.

DOLATABADI, E.; TAATI, B.; MIHAILIDIS, A. Concurrent validity of the Microsoft Kinect for Windows v2 for measuring spatiotemporal gait parameters. Med Eng Phys, v. 38, n. 9, p. 952-8, Sep 2016. ISSN 1350-4533. 
DUNCAN, M. J. et al. Coincidence Anticipation Timing Performance during an Acute Bout of Brisk Walking in Older Adults: Effect of Stimulus Speed. Neural Plasticity, 2015. ISSN 2090-5904.

FERNANI, D. C. G. L. et al. Motor intervention on children with school learning dificulties. Journal of Human Growth and Development, v. 23, n. 2, p. 209-214, 2013. ISSN 0104-1282.

FOSTER, H.; POPPLEWELL, L.; DICKSON, G. Genetic therapeutic approaches for Duchenne muscular dystrophy. Hum Gene Ther, v. 23, n. 7, p. 676-87, Jul 2012. ISSN 1043-0342.

FUNG, V. et al. Use of Nintendo Wii Fit in the rehabilitation of outpatients following total knee replacement: a preliminary randomised controlled trial. Physiotherapy, v. 98, n. 3, p. 183-8, Sep 2012. ISSN 0031-9406.

GOLOMB, M. R. et al. In-home virtual reality videogame telerehabilitation in adolescents with hemiplegic cerebral palsy. Arch Phys Med Rehabil, v. 91, n. 1, p. 18.e1, Jan 2010. ISSN 0003-9993.

GUARNIERI, R. et al. Test-Retest Reliability and Clinical Feasibility of a MotionControlled Game to Enhance the Literacy and Numeracy Skills of Young Individuals with Intellectual Disability. Cyberpsychol Behav Soc Netw, v. 22, n. 2, p. 111-121, Feb 2019. ISSN 2152-2715.

GUIRAUD, S. et al. The Pathogenesis and Therapy of Muscular Dystrophies. Annu Rev Genomics Hum Genet, v. 16, p. 281-308, 2015. ISSN 1527-8204.

GUTH, D. Space saving statistics - an introduction to constant error, variable error, and absolute error. Peabody Journal of Education, v. 67, n. 2, p. 110-120, Win 1990. ISSN 0031-3432.

HASHIMOTO, Y. et al. Change in brain activity through virtual reality-based brainmachine communication in a chronic tetraplegic subject with muscular dystrophy. BMC Neurosci, v. 11, p. 117, Sep 16 2010. ISSN 1471-2202. 
HIRAKATA, V. N.; CAMEY, S. A. Análise de concordância entre métodos de BlandAltman. Revista HCPA. Porto Alegre. Vol. 29, no. 3 (2009), p. 261-268., 2009. ISSN 0101-5575.

HUGHES, K. J. et al. Physical exertion exacerbates decline in the musculature of an animal model of Duchenne muscular dystrophy. Proceedings of the National Academy of Sciences of the United States of America, v. 116, n. 9, p. 3508, 2019.

HUKUDA, M. E. et al. Evaluation scale development, reliability for sitting and standing from the chair for Duchenne muscular dystrophy. J Mot Behav, v. 45, n. 2, p. 117-26, 2013. ISSN 0022-2895.

JALINK, M. et al. Construct and concurrent validity of a Nintendo Wii video game made for training basic laparoscopic skills. Surgical endoscopy, v. 28, n. 2, p. 537542, 2014. ISSN 0930-2794.

JUNG, I. Y. et al. The correlation analysis of functional factors and age with duchenne muscular dystrophy. Ann Rehabil Med, v. 36, n. 1, p. 22-32, Feb 2012. ISSN 2234-0645.

KIRNER, C.; SISCOUTTO, R. Realidade virtual e aumentada: conceitos, projeto e aplicações. Livro do IX Symposium on Virtual and Augmented Reality, Petrópolis (RJ), Porto Alegre: SBC, 2007.

KOLBER, M. J. et al. The reliability and concurrent validity of measurements used to quantify lumbar spine mobility: an analysis of an iphone $₫$ application and gravity based inclinometry. International journal of sports physical therapy, v. 8, n. 2, p. 129, 2013.

KOO, T. K.; LI, M. Y. A Guideline of Selecting and Reporting Intraclass Correlation Coefficients for Reliability Research. J Chiropr Med, v. 15, n. 2, p. 155-63, Jun 2016. ISSN 1556-3707 (Print) 1556-3707.

KORNEGAY, J. N. The golden retriever model of Duchenne muscular dystrophy. Skelet Muscle, v. 7, n. 1, p. 9, May 19 2017. ISSN 2044-5040. 
LAFAYETTE. Bassin Anticipation Timer User's Manual. COMPANY, L. I. EUA 2008.

LAI, P. Validating instruments of measure: Is it really necessary? Malaysian family physician : the official journal of the Academy of Family Physicians of Malaysia, v. 8, n. 1, p. 2, 2013. ISSN 1985-207X.

LARSSON, M.; SANDBERG, A.; SMITH, M. Reading and Spelling in Children with Severe Speech and Physical Impairments. Journal of Developmental and Physical Disabilities, Boston, v. 21, n. 5, p. 369-392, 2009. ISSN 1056-263X.

LEYS, C. et al. Detecting outliers: Do not use standard deviation around the mean, use absolute deviation around the median. Journal of Experimental Social Psychology, v. 49, n. 4, p. 764-766, 2013. ISSN 0022-1031.

LINDSAY, A. et al. Isometric resistance training increases strength and alters histopathology of dystrophin-deficient mouse skeletal muscle. Journal of Applied Physiology, v. 126, n. 2, p. 363-375, Feb 2019. ISSN 8750-7587.

LYONS, M.; AL-NAKEEB, Y.; NEVILL, A. Post-exercise coincidence anticipation in expert and novice Gaelic games players: the effects of exercise intensity. European Journal of Sport Science, v. 8, n. 4, p. 205-216, 2008. ISSN 1746-1391.

MADARY, M.; METZINGER, T. K. Real virtuality: a code of ethical conduct. Recommendations for good scientific practice and the consumers of VR-technology. Frontiers in Robotics and AI, v. 3, p. 3, 2016. ISSN 2296-9144.

MALHEIROS, S. R. et al. Computer task performance by subjects with Duchenne muscular dystrophy. Neuropsychiatr Dis Treat, v. 12, p. 41-8, 2016. ISSN 1176-6328 (Print) 1176-6328.

MALIK, V.; RODINO-KLAPAC, L. R.; MENDELL, J. R. Emerging drugs for Duchenne muscular dystrophy. Expert Opin Emerg Drugs, v. 17, n. 2, p. 261-77, Jun 2012. ISSN 1472-8214. 
MAROCO, J.; GARCIA-MARQUES, T. Qual a fiabilidade do alfa de Cronbach? Questões antigas e soluções modernas? Laboratório de psicologia, p. 65-90, 2006. ISSN 1645-7927.

MASAKI, H. et al. Neural mechanisms of timing control in a coincident timing task. Exp Brain Res, v. 218, n. 2, p. 215-26, Apr 2012. ISSN 0014-4819.

MASSETTI, T. et al. Achievement of Virtual and Real Objects Using a Short-Term Motor Learning Protocol in People with Duchenne Muscular Dystrophy: A Crossover Randomized Controlled Trial. Games for Health Journal, v. 7, n. 2, p. 107-115, Apr 2018. ISSN 2161-783X.

MCCOMAS, J.; MACKAY, M.; PIVIK, J. Effectiveness of virtual reality for teaching pedestrian safety. Cyberpsychol Behav, v. 5, n. 3, p. 185-90, Jun 2002. ISSN 10949313 (Print) 1094-9313.

MERLINI, L. et al. Early corticosteroid treatment in 4 Duchenne muscular dystrophy patients: 14-year follow-up. Muscle Nerve, v. 45, n. 6, p. 796-802, Jun 2012. ISSN 0148-639x.

MUNIH, M. et al. Force exertion capacity measurements in haptic virtual environments. Int J Rehabil Res, v. 33, n. 1, p. 34-42, Mar 2010. ISSN 0342-5282.

NAKAMOTO, $\mathrm{H}$. et al. Effects of sport expertise on representational momentum during timing control. Attention Perception \& Psychophysics, v. 77, n. 3, p. 961-971, Apr 2015. ISSN 1943-3921.

NASCIMENTO, L. P. et al. Development of a new haptic perception instrument: a pilot study. Arq Neuropsiquiatr, v. 74, n. 1, p. 75-80, Jan 2016. ISSN 0004-282x.

NEISTADT, M. E.; CREPEAU, E. B. Willard \& Spackman: Terapia ocupacional. Nona edição, 2002.

OKORO, C. A. et al. Prevalence and correlates of depressive symptoms among 
United States adults with disabilities using assistive technology. Prev Med, v. 50, n. 4, p. 204-9, Apr 2010. ISSN 0091-7435.

PEDDAREDDYGARI, L. R. et al. Phenotype-genotype analysis of dystrophinopathy caused by duplication mutation in Dystrophin gene in an African patient. Afr Health Sci, v. 11, n. 4, p. 607-9, Dec 2011. ISSN 1680-6905.

PEIJNENBORGH, J. et al. A Study on the Validity of a Computer-Based Game to Assess Cognitive Processes, Reward Mechanisms, and Time Perception in Children Aged 4-8 Years. Jmir Serious Games, v. 4, n. 2, Jul-Dec 2016. ISSN 2291-9279.

QUADRADO, V. H. et al. Motor learning from virtual reality to natural environments in individuals with Duchenne muscular dystrophy. Disabil Rehabil Assist Technol, p. 1-9, Nov 10 2017. ISSN 1748-3107.

RAMAN, V.; YACOB, D.; TOBIAS, J. D. Dexmedetomidine-ketamine sedation during upper gastrointestinal endoscopy and biopsy in a patient with Duchenne muscular dystrophy and egg allergy. Int J Crit IIIn Inj Sci, v. 2, n. 1, p. 40-3, Jan 2012. ISSN 2229-5151.

RAYMUNDO, V. P. Construção e validação de instrumentos: um desafio para a psicolinguística. Letras de Hoje, v. 44, n. 3, p. 86-93, 2009. ISSN 1984-7726.

RIZZO, A.; SHILLING, R. Clinical Virtual Reality tools to advance the prevention, assessment, and treatment of PTSD. Eur J Psychotraumatol, v. 8, n. sup5, p. 1414560, 2017. ISSN 2000-8066 (Print) 2000-8066.

SANDERS, G. Sex differences in coincidence-anticipation timing (CAT): a review. Percept Mot Skills, v. 112, n. 1, p. 61-90, Feb 2011. ISSN 0031-5125 (Print) 0031-5125.

SANDERS, G.; SINCLAIR, K. Sex Differences in Accuracy and Precision When Judging Time to Arrival: Data from Two Internet Studies. Archives of Sexual Behavior, Boston, v. 40, n. 6, p. 1189-1198, 2011. ISSN 0004-0002. 
SCHWEBEL, D. C. et al. Community-based pedestrian safety training in virtual reality: A pragmatic trial. Accid Anal Prev, v. 86, p. 9-15, Jan 2016. ISSN 0001-4575.

SCHWEBEL, D. C.; MCCLURE, L. A.; SEVERSON, J. Teaching children to cross streets safely: a randomized, controlled trial. Health Psychol, v. 33, n. 7, p. 628-38, Jul 2014. ISSN 0278-6133.

SHIH, C. H.; SHIH, C. T.; CHU, C. L. Assisting people with multiple disabilities actively correct abnormal standing posture with a Nintendo Wii balance board through controlling environmental stimulation. Res Dev Disabil, v. 31, n. 4, p. 936-42, Jul-Aug 2010. ISSN 0891-4222.

SILVA, E. C. et al. Motor function measure scale, steroid therapy and patients with Duchenne muscular dystrophy. Arq Neuropsiquiatr, v. 70, n. 3, p. 191-5, Mar 2012. ISSN 0004-282x.

STANDEN, P. J.; BROWN, D. J. Virtual reality in the rehabilitation of people with intellectual disabilities: review. Cyberpsychol Behav, v. 8, n. 3, p. 272-82; discussion 283-8, Jun 2005. ISSN 1094-9313 (Print) 1094-9313.

STREINER, D. L. Being inconsistent about consistency: When coefficient alpha does and doesn't matter. Journal of personality assessment, v. 80, n. 3, p. 217-222, 2003. ISSN 0022-3891.

SULLIVAN, G. M. A primer on the validity of assessment instruments. Journal of graduate medical education, v. 3, n. 2, p. 119, 2011.

THOMSON, J. A. et al. Influence of virtual reality training on the roadside crossing judgments of child pedestrians. J Exp Psychol Appl, v. 11, n. 3, p. 175-86, Sep 2005. ISSN 1076-898X (Print) 1076-898x.

TONG, T. et al. A serious game for clinical assessment of cognitive status: validation study. JMIR serious games, v. 4, n. 1, 2016.

VAN DER WEEL, F. R.; VAN DER MEER, A. L.; LEE, D. N. Effect of task on 
movement control in cerebral palsy: implications for assessment and therapy. Dev Med Child Neurol, v. 33, n. 5, p. 419-26, May 1991. ISSN 0012-1622 (Print) 00121622.

VESTERGAARD, P. et al. Fracture risk in patients with muscular dystrophy and spinal muscular atrophy. J Rehabil Med, v. 33, n. 4, p. 150-5, Jul 2001. ISSN 16501977 (Print) 1650-1977.

VIGNOS, P. J., JR.; ARCHIBALD, K. C. Maintenance of ambulation in childhood muscular dystrophy. J Chronic Dis, v. 12, p. 273-90, Aug 1960. ISSN 0021-9681 (Print) 0021-9681.

VILOZNI, D. et al. Computerized respiratory muscle training in children with Duchenne muscular dystrophy. Neuromuscul Disord, v. 4, n. 3, p. 249-55, May 1994. ISSN 0960-8966 (Print) 0960-8966.

VISSER, J. Developmental coordination disorder: a review of research on subtypes and comorbidities. Hum Mov Sci, v. 22, n. 4-5, p. 479-93, Nov 2003. ISSN 0167-9457 (Print) 0167-9457.

WEISS, P. L. et al. Video capture virtual reality as a flexible and effective rehabilitation tool. J Neuroeng Rehabil, v. 1, n. 1, p. 12, Dec 20 2004. ISSN 17430003.

YIU, E. M.; KORNBERG, A. J. Duchenne muscular dystrophy. J Paediatr Child Health, v. 51, n. 8, p. 759-64, Aug 2015. ISSN 1034-4810. 
ANEXOS

ANEXO A - Comitê de Ética

ANEXO B - Paper 
ANEXO A

Comitê de Ética

\section{USP - FACULDADE DE \\ MEDICINA DA UNIVERSIDADE \\ DE SÃO PAULO - FMUSP}

\section{PARECER CONSUBSTANCIADO DO CEP}

\section{DADOS DO PROJETO DE PESQUISA}

Título da Pesquisa: VALIDADE E CONFIABILIDADE DE SOFTWARE VIRTUAL EM TECNOLOGIA ASSISTIVA PARA PESSOAS COM DISTROFIA MUSCULAR DE DUCHENNE

Pesquisador: Carlos Bandeira de Mello Monteiro

Área Temática:

Versão: 1

CAAE: 64307417.3.0000.0065

Instituição Proponente: Faculdade de Medicina da Universidade de São Paulo

Patrocinador Principal: Financiamento Próprio

\section{DADOS DO PARECER}

Número do Parecer: 1.954.118

Apresentação do Projeto:

Trata-se de uma tese de doutorado. O projeto apresentado para a admissão no programa de doutorado está bem apresentado, a seção de materiais e métodos bem descrita e a proposta é suportada por fria bibliografia.

\section{Objetivo da Pesquisa:}

A pesquisa pretende estudar a validade e confiabilidade de software virtual em tecnologia assistiva para pessoas com Distrofia Muscular de Duchenne (DMD).

Avaliação dos Riscos e Benefícios:

Não há riscos importantes.

Comentários e Considerações sobre a Pesquisa:

A DMD é uma doença genética hereditária caracterizada essencialmente pelo enfraquecimento progressivo e irreversível da musculatura. Qualquer pesquisa que possa ajudar os profissionais da saúde a minorar ou retardar seus efeitos é importante.

Considerações sobre os Termos de apresentação obrigatória:

São apresentados ECLE e TALE. Ambos tem linguagem adequada.

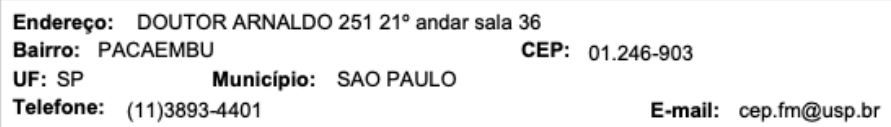




\section{USP - FACULDADE DE MEDICINA DA UNIVERSIDADE DE SÃO PAULO - FMUSP}

Continuaçāo do Parecer: 1.954 .118

Conclusões ou Pendências e Lista de Inadequações:

Projeto sem problemas éticos.

Considerações Finais a critério do CEP:

Este parecer foi elaborado baseado nos documentos abaixo relacionados:

\begin{tabular}{|c|c|c|c|c|}
\hline Tipo Documento & Arquivo & Postagem & Autor & Situação \\
\hline $\begin{array}{l}\begin{array}{l}\text { Informações Básicas } \\
\text { do Projeto }\end{array} \\
\end{array}$ & $\begin{array}{l}\text { PB_INFORMAÇŐES_BÁSICAS_DO_P } \\
\text { ROJETO 844706.pdf }\end{array}$ & $\begin{array}{c}01 / 02 / 2017 \\
17: 45: 56 \\
\end{array}$ & & Aceito \\
\hline $\begin{array}{l}\text { TCLE / Termos de } \\
\text { Assentimento / } \\
\text { Justificativa de } \\
\text { Ausência } \\
\end{array}$ & TALE.pdf & $\begin{array}{c}01 / 02 / 2017 \\
17: 09: 53\end{array}$ & THAISS MASSETTI & Aceito \\
\hline $\begin{array}{l}\text { TCLE / Termos de } \\
\text { Assentimento / } \\
\text { Justificativa de } \\
\text { Ausência }\end{array}$ & TCLE.pdf & $\begin{array}{c}01 / 02 / 2017 \\
17: 06: 14\end{array}$ & THAIS MASSETTI & Aceito \\
\hline Outros & protocolopesquisa.pdf & $\begin{array}{c}01 / 02 / 2017 \\
16: 02: 44 \\
\end{array}$ & THAIS MASSETTI & Aceito \\
\hline Folha de Rosto & folhaderosto01.pdf & $\begin{array}{c}01 / 02 / 2017 \\
16: 01: 18 \\
\end{array}$ & THAÍS MASSETTI & Aceito \\
\hline $\begin{array}{l}\text { Projeto Detalhado / } \\
\text { Brochura } \\
\text { Investigador }\end{array}$ & Doutorado.pdf & $\begin{array}{c}15 / 12 / 2016 \\
16: 59: 26\end{array}$ & THAIS MASSETTI & Aceito \\
\hline
\end{tabular}

Situação do Parecer:

Aprovado

Necessita Apreciação da CONEP:

Não

SAO PAULO, 08 de Março de 2017

Assinado por:

Maria Aparecida Azevedo Koike Folgueira

(Coordenador)

Endereço: DOUTOR ARNALDO $25121^{\circ}$ andar sala 36

CEP: $01.246-903$

UF: SP

Municipio: SAO PAULO

Telefone: (11)3893-4401

E-mail: cep.fm@usp.br 
ANEXO B - Paper

\title{
VALIDITY AND RELIABILITY OF VIRTUAL SOFTWARE WITH A TIMING COINCIDENT TASK FOR PERSONS WITH DUCHENNE MUSCULAR DYSTROPHY.
}

\begin{abstract}
Background: Duchenne muscular dystrophy (DMD) is a recessive genetic disease, characterized by progressive and irreversible weakening of the musculature, leading to a serious physical disability. Objective: The objective of this study is to perform the validation of an instrument that evaluates a coincident-anticipation timing (CAT) task using a non-immersive virtual reality task in person with DMD. Methods: A prospective, observational, no experimental design was used. We analyzed 91 participants, consisted of 31 DMD and 60 typically development participants. To perform the concurrent validation we use two instruments, the Bassin Anticipation Timer (Bassin) and the Coincident Timing in Team Bridge games (Bridge). Results: Bridge and Bassin showed acceptable blocks score internal consistencies, ranging from $\alpha=.80$ to $\alpha=.97$ for Bridge, and $\alpha=.67$ to $\alpha=.91$ for Bassin. The intraclass correlation coefficient to measure the reliability of the rating scores for Bridge and Bassin were between 0.66 and 0.82. The Pearson correlation between the Bridge and Bassin, in terms of the blocks, mean differences, showed the excellent relationship between blocks for TD group in absolute error (AE) and constant error (EC) with exception of transfer block. The DMD group showed excellent relationship only in B13 and B14 in AE and CE. No relationship was found in all blocks of VE. Conclusion: The Coincident Timing task in Team Bridge games presented acceptable validity been a viable option to anticipation timing task measurement.
\end{abstract}

Keywords: muscular dystrophies; muscular dystrophy, Duchenne; motor skills; virtual reality exposure therapy; rehabilitation; user-computer interface; validation.

Trial Registration: the trial is registered at the ClinicalTrials.gov Identifier: NCT03002298 


\section{BACKGROUND}

Duchenne muscular dystrophy (DMD) is a lethal X-linked recessive neuromuscular disorder caused by mutations in the dystrophin gene that result in absent or insufficient functional dystrophin, a cytoskeletal protein that enables the strength, stability, and functionality of myofibres ${ }^{1}$. The worldwide incidence is estimated at 1: 5000 male newborns ${ }^{2}$. Birth prevalence ranged from 15.9 to 19.5 per 100,000 live births in USA and 19.5 cases per 100000 live male births in the UK. This number is not conclusive in Brazil.

The progressive muscle weakness results in respiratory, orthopedic, and cardiac complications, and without intervention can eventually lead to death around 19 years ${ }^{3}$. Thus, in order to minimize the consequences of the disease progression, Bushby $\mathrm{K}$ et al $(2010)^{3}$ presented that a coordinated multidisciplinary approach to care is essential for DMD. Therefore, an interest in using assistive technology has advanced rapidly over the last decade, as an aid in teaching new skills to people with disabilities as a permanent support or used as a temporary aid. According to NEISTADT \& CREPEAU, $2002^{4}$ assistive technology can be defined as any ready-to-use, tailor-made, or tailor-made item, piece, or product that is used to maintain or enhance the functional capabilities of persons.

Considering different possibilities of assistive technology, a new approach that has been used in rehabilitation is the modernity proposed by virtual reality (VR) environments. It can provide a safe setting to practice skills that might carry too many risks in the real world ${ }^{5}$, and possesses many possibilities to improve performance for the person with motor or intellectual disabilities, acting as an assessment and intervention tool. According to ${ }^{6}$ virtual reality supported by modern technologies can be used as a form of physical, cognitive or psychological intervention that is based on the use of games and virtual environment tasks to enable a function to people with disabilities, such as DMD.

Currently, some studies have been done using VR in DMD for respiratory muscle training using video game ${ }^{7}$ and for upper limb motor improvement using the smartphone ${ }^{8}$ and both found positive results of the technologies used. We advocate that this technology could be used to promote function and extend the motor function of people with DMD.

Despite the existing studies with the use of virtual reality in DMD, a new possibility that arises is the creation of virtual tasks that can measure difficulties presented by disabled people and replace existing real instruments. ${ }^{9}$, presented that real measurements instruments are important for practice but the difficulty of transportation (considering the size of the device), price and space required to use makes it difficult to carry out research and practical 
applicability. Thus, the development of virtual tasks similar to the real ones that offer the same information should be stimulated ${ }^{10}$.

In this context, with regard to assessment, a real instrument widely used in research is the Bassin Anticipatory Model (from Lafayette Instrument Corporation) which was developed to evaluate coincident timing performance in a real laboratory environment. ${ }^{11}$ defined coincident timing task as the perceptual-motor ability to execute a motor response in synchrony with the arrival of an external object at a given point. With the objective of measuring the coincident timing, several studies used the Bassin device ${ }^{12}$ in people with typical development 13-16 especially interest with athletes ${ }^{14,17,18}$ and some studies with disabled people ${ }^{19-21}$.

However, instead of using a real instrument, the software Team Bridge Games was developed to enable similar task, named Coincident Timing game ${ }^{22}$, in a non-immersive virtual environment providing easy access, handling, transport, engaging kind of application (considering the ludic characteristic of VR) and with a differential of enabling the therapist to control variables such as object speed, size and color.

The software was recently used in research with healthy people, Autism spectrum disorder, cerebral palsy, Asperger and Alzheimer ${ }^{22}$, elderly ${ }^{23}$. The results demonstrated interesting adaptation to the system by all participants with improvement of performance during practice. The first validation was conduct by Crocetta et al (in review) ${ }^{24}$ in healthy subjects. The early version of this software was used in Cerebral Palsy ${ }^{25}$ and DMD (see ${ }^{26}$. However, a validation with DMD was not made yet. An instrument is valid when its construction and application apply to a faithful measurement of what it is intended to measure ${ }^{27}$. According to 28 to use a new device, a previous validation is always important to support and make effective the results obtained in the use of new evaluation and intervention systems. Validity refers to the accuracy of the instrument, that is, to the ability to accurately measure what it proposes to measure ${ }^{27}$.

Considering the above deliberations, the objective of this study is to perform the validation of an instrument that evaluates the coincident timing by means of a non-immersive virtual reality task in people with DMD. Validation is considered an important factor to support the use of a new instrument with particular characteristics population and has been done with a different device in DMD 29-31.

To enable this issue, we will evaluate people with typical development and with DMD practicing both tasks, i.e. non-immersive virtual reality (using the virtual reality software) and using a concurrent validation (comparing with the traditional Bassin Anticipation test) used as criteria for determining the validity. 
We were especially interested in finding out if the software with the coincident timing task can be used with people with DMD and provide accurate data. We can hypothesize that the results will demonstrate the possibility to use a non-immersive virtual reality task - to measure the motor performance of people with DMD with equivalent (competition) and internal consistency ${ }^{32}$. If the hypothesis is proven, it will be important to have a valid software that allows the measurement of the coincident timing of the person with DMD, which will not only aid for research, but also as an evaluation system in clinical practice.

\section{METHODS}

A prospective, observational, nonexperimental design was used.

\section{Ethics}

This research was approved by the Universidade de Sao Paulo and Faculdade de Medicina do ABC ethics committees - CAAE: 64307417.3.0000.0065 and 39396814.9.1001.0082, respectively. All participants signed informed assent forms and, their parents signed a consent form. Participants should sign the assent form (for minors) ${ }^{33}$ and their legal representatives signed the informed consent form.

\section{Participants}

DMD group consisted of 31 Duchenne muscular dystrophy participants from a public rehabilitation institution (AACD), São Paulo, Brazil, varied in age between 10 and 18 years, with a mean of 14.72 years $(\mathrm{SD}=2.28)$. The control group consisted of 60 typically development participants from regular public schools, São Paulo, Brazil, with age between 8 and 18 years, with a mean of 13.78 years $(\mathrm{SD}=2.98)$.

All individuals with the diagnosis of DMD confirmed by the molecular method and/or by protein expression of skeletal muscle were considered eligible.

Exclusion criteria were disturbances in cognitive function that would impede comprehension of the instruction of the task proposed by the two instruments.

For the characterization of individuals with DMD, the Vignos scale ${ }^{34}$, which characterizes the staging of the disease, according to the milestones of the disease evolution, using a score from 1 to 10 , the higher is the patient's impairment, i.e. 1 (walks and climbs unassisted stairs) to 10 (confined to the bed). Motor Function Measurement Scale (MFM), which quantitatively evaluates motor function, was also used to describe motor deficits, consisting of 32 tasks, divided into three domains that provide a detailed profile of the physical 
disability: (D1) standing and transfer; (D2) axial and proximal motor capacity and (D3) distal motor capacity ${ }^{35}$. (see Table 1 )

Two of participants were excluded from statistical analysis because they did not conclude all test sessions.

Table 1. Individuals diagnosed with Duchenne muscular dystrophy who participated in this study (total of 29 individuals).

\begin{tabular}{lccccccc}
\hline & Age & Vignos & $\begin{array}{c}\text { MFM } \\
\text { D1 }\end{array}$ & $\begin{array}{c}\text { MFM } \\
\text { D2 }\end{array}$ & $\begin{array}{c}\text { MFM } \\
\text { D3 }\end{array}$ & $\begin{array}{c}\text { MFM } \\
\text { TOTAL }\end{array}$ & EK \\
\hline Mean & 14.72 & 6 & 18.76 & 76.00 & 81.90 & 55.01 & 6.57 \\
Min/Max & $10 / 18$ & $2 / 8$ & $0 / 69$ & $41 / 100$ & $47 / 100$ & $28 / 95$ & $2 / 15$ \\
$\begin{array}{l}\text { Standard } \\
\text { deviation }\end{array}$ & 2.28 & 2.32 & 24.48 & 18.99 & 13.95 & 19.28 & 4.78 \\
\hline
\end{tabular}

Vignos: Vignos scale; MFM: Motor Function Measurement Scale; D1: standing and transfer domain; D2: axial and proximal motor capacity domain; D3: distal motor capacity domain; EK: Egen Klassifikation; Min: Minimum; Max: Maximum.

\section{Instruments}

\section{Bassin Anticipation Timer (real task)}

Bassin Anticipation Timer Model 35580 (Lafayette Instrument, Indiana, USA) was used to represent the real environment, as used in several studies ${ }^{12}$. This equipment was developed to test the area of visual acuity related to eye-hand coordination and anticipation. The participant was instructed to watch a light as it travels down the runway with 32 LEDs (two runways with 16 red LEDs on each). A cue yellow LED was lit for 0.5 seconds after initiating a test and before the lights run down the runway. The participant must anticipate the light reaching the target (last LED) and press a pushbutton to coincide with the arrival of the light at the target. The LCD readout displays the time difference between the response and the arrival of the light at the target and indicates if the response was early or late. (Figure 1) The Bassin Anticipation Timer is the standard instrument for use in coincidence-anticipation timing measurements ${ }^{12}$. 


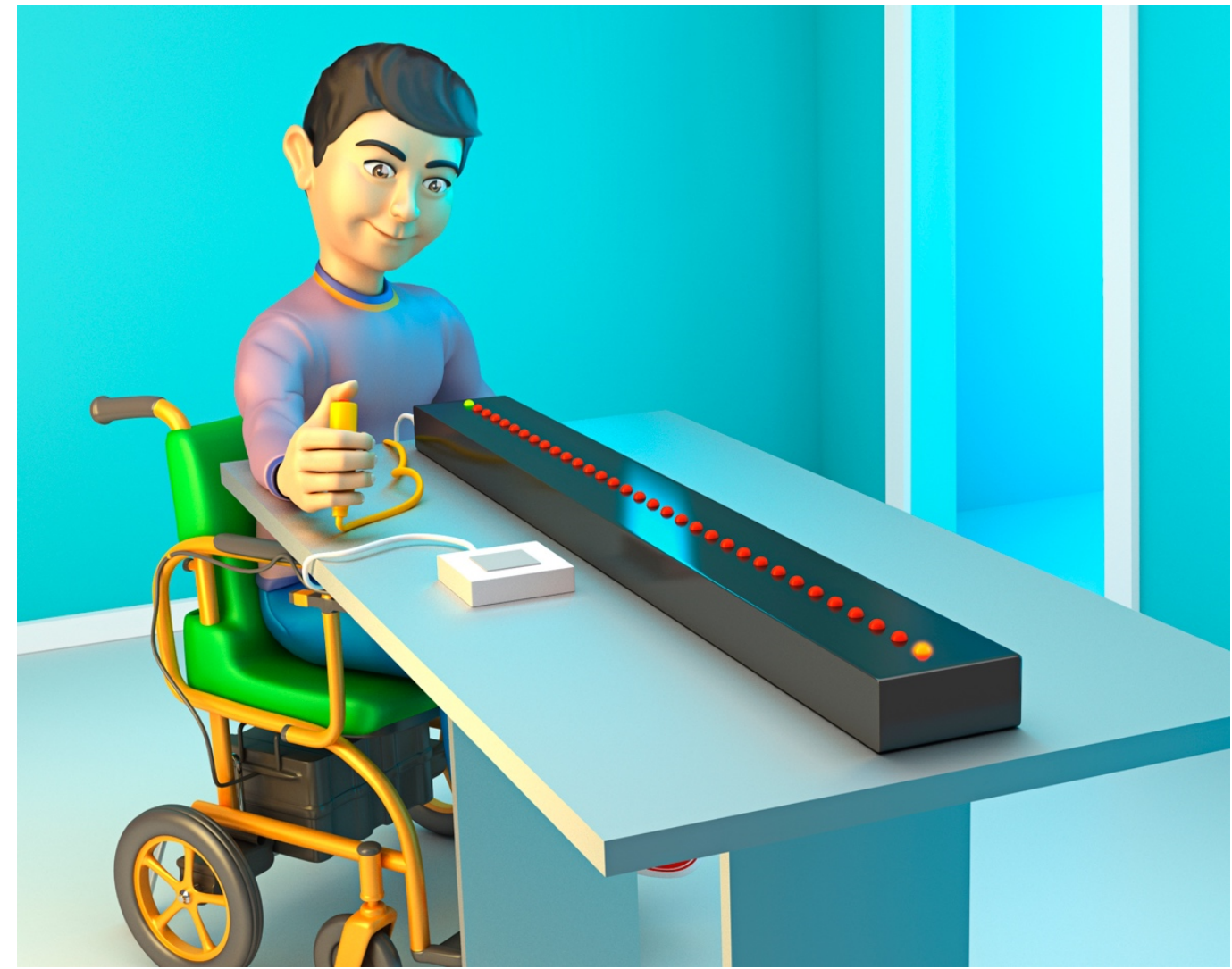

Figure 1. The participant during the execution of Bassin Anticipation Timer with a push button in the hand.

\section{Coincident Timing game in Team Bridge Game Software (virtual task)}

In the non-immersive virtual purpose, 10 bubbles in 3D are displayed on the computer screen which illuminates (red light) in sequence until reaching the last bubble that is considered the target. To complete the task the participant presses the space bar when the light gets the last bubble (Figure 2), software details see Crocetta et al $2017^{22}$. The Coincident Timing game software was validated in healthy adults by Crocetta et al. (in review) ${ }^{24}$. 


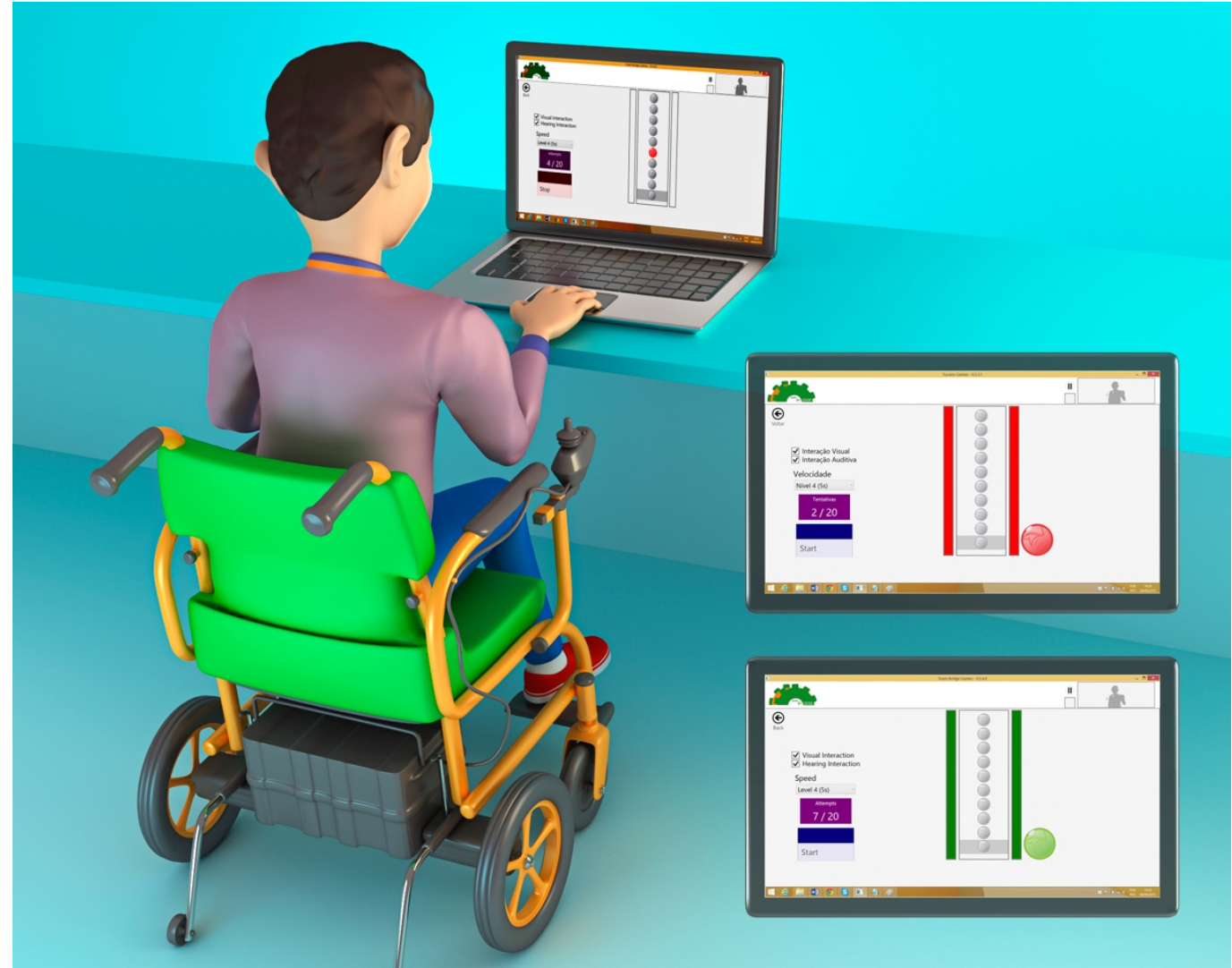

Figure 2. The participant during the execution of Coincident Timing game in the Team Bridge games package.

\section{Procedures}

Each participant was tested individually in a quiet room on the Coincident Timing game 22 and the Bassin Anticipation Timer apparatus on the same day. The order of administering the two tests was counterbalanced. At least one break was offered to the participants between tests. (Figure 3). 


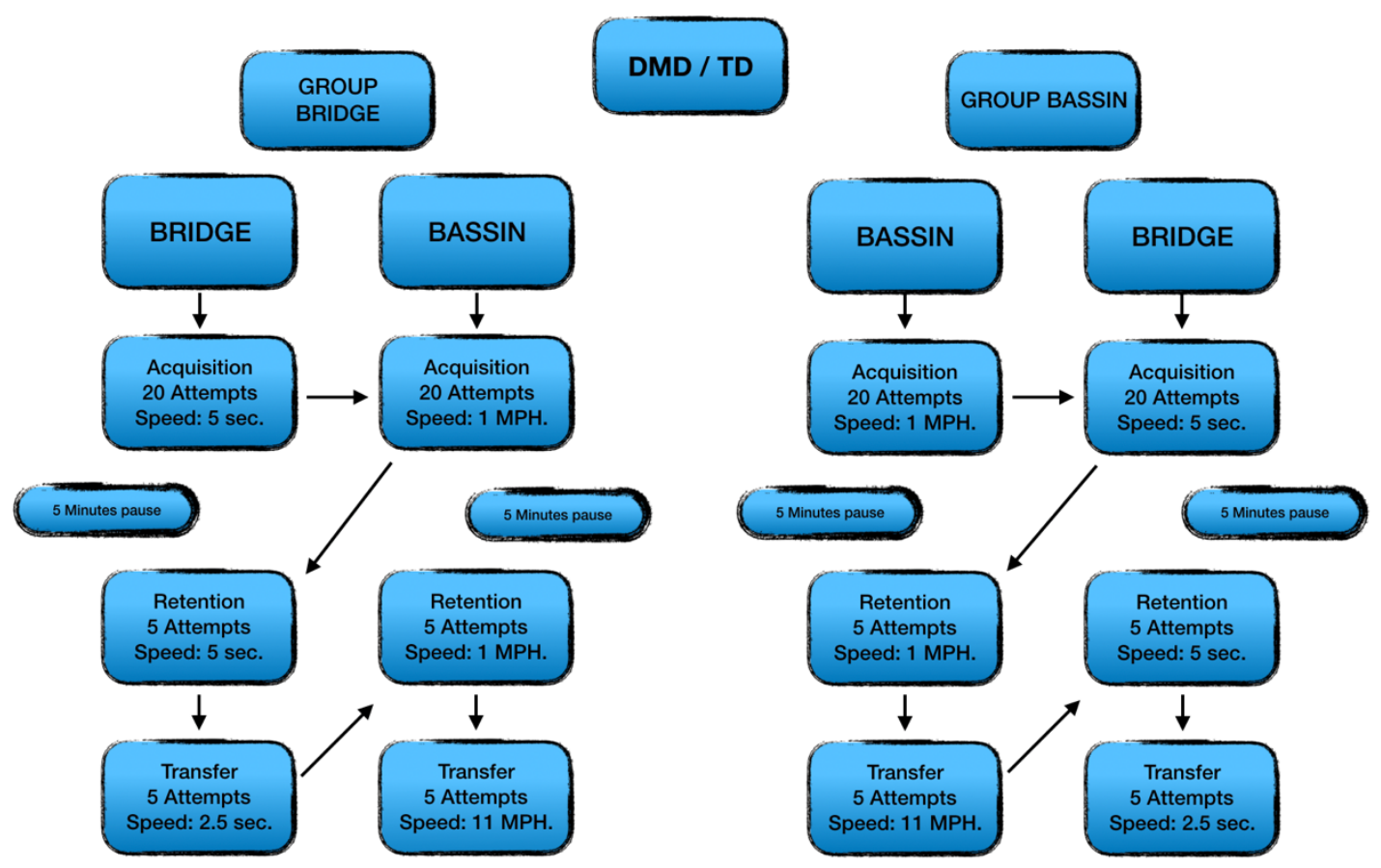

Legend: DMD: Duchenne muscular dystrophy; TD: typical development

Figure 3. Study design

The protocol was based on motor learning, this, in turn, is a phenomenon that refers to the internal changes, relatively permanent, involved in the ability to perform motor skills, the practical experience results in the acquisition, retention, and transfer of motor skills ${ }^{36}$. Motor learning can be inferred through performance, while its improvement can be observed by increasing consistency, fluency in movement, reduction of execution error and reduction in total movement time to perform the task ${ }^{37}$.

\section{Data Analysis}

IBM-SPSS version 20.0.0 (IBM Corp., Armonk, NY, USA) was used for data analysis. Bland-Altman plots were calculated with R software, version 3.1.2 (R Foundation for Statistical Computing, Vienna, Austria - http://www.r-project.org) using routines proposed by Hirakata \& Camey $(2009)^{38}$. The study population and clinical characteristics were defined using descriptive statistics.

The scores for Bassin and Bridge were calculated using blocks (mean of five attempts each) for all study phases (four blocks during the acquisition, one block in the retention, and one block in the transfer phases). These were presented as means and standard deviations. For every five attempts, the absolute error (AE), constant error (CE) and variable error (VE) were 
calculated using the formulas described by Monteiro et al $(2017)^{9}$.

Internal consistency for Cronbach's alpha with values ranging from 0.7 to 0.8 was considered as being satisfactory, with a minimal of 0.9 as desirable ${ }^{39}$.

The intraclass correlation coefficient (ICC) with the value less than 0.5 was indicative of poor reliability, while values between 0.5 and 0.75 indicated moderate reliability; values between 0.75 and 0.9 indicated good reliability and values greater than 0.90 indicated excellent reliability ${ }^{40}$.

Bland-Altman plots were generated to provide a visual representation of the difference between the Bridge and Bassin. The levels of agreement between Bridge and Bassin were expressed as intraclass correlation coefficients (ICCs) of the type $(2, \mathrm{k})$, associated 95\% confidence intervals (CI), and Spearman rank correlation coefficients. Statistical significance was set at $\mathrm{p}<0.05$.

Treatment methods for outliers. The outliers were removed using the median plus or minus 2.5 times the median absolute deviation (MAD) method for outlier detection proposed by Leys et al. $(2013)^{41}$.

\section{RESULTS}

There were no significant differences between groups for age (Duchenne muscular dystrophy $=14.72 \pm 2.28$; typically developed $=13.78 \pm 2.98, \mathrm{p}=.23$ ).

The means, internal consistency and intraclass correlation coefficients (ICC) of reliabilities of the coincident-anticipation timing (CAT) tasks scores in each block of absolute error, constant error and variable error (AE, CE, and VE, respectively) are presented in Table 2. When considered together, Bridge and Bassin showed acceptable blocks score internal consistencies, ranging from $\alpha=.75$ to $\alpha=.84$ for Duchenne muscular dystrophy (DMD) group, and $\alpha=.74$ to $\alpha=.89$ for typically development (TD) group. The TD had the higher internal consistency on $\mathrm{AE}$ and $\mathrm{CE}$ blocks ( $\alpha=.89$ for both $\mathrm{AE}$ and $\mathrm{CE}$ ) and DMD with $\alpha=.84$ for $\mathrm{AE}$, and $\alpha=.81$ to CE. The internal consistencies of the VE showed the lower scores in both groups, with $\alpha=.75$ for DMD and $\alpha=.74$ for TD. 
Table 2. Block score means, standard deviations, internal consistency, and concurrent validity in both coincident-anticipation timing tasks, presented by the group and absolute, constant and variable error.

\begin{tabular}{|c|c|c|c|c|c|c|}
\hline & \multicolumn{3}{|c|}{$\begin{array}{c}\text { Duchenne muscular dystrophy } \\
\mathbf{n}=29\end{array}$} & \multicolumn{3}{|c|}{$\begin{array}{l}\text { Typically, development } \\
n=60\end{array}$} \\
\hline & $\mathbf{A E}$ & $\mathbf{C E}$ & $\mathbf{V E}$ & $\mathbf{A E}$ & $\mathbf{C E}$ & VE \\
\hline \multicolumn{7}{|c|}{ Coincident Timing game in Team Bridge games package (Bridge) } \\
\hline Bl1 & $300.95+117.13$ & $299.89 \pm 115.49$ & $100.08+132.50$ & $444.31+363.07$ & $427.43+348.63$ & $133.70+207.40$ \\
\hline B12 & $317.84+207.85$ & $316.34 \pm 209.57$ & $97.54+\overline{9} 5.60$ & $453.05 \pm 393.83$ & $413.12+387.37$ & $131.30 \pm 281.45$ \\
\hline BI3 & $307.37+114.43$ & $306.43+111.47$ & $100.2 \overline{2}+109.14$ & $431.39+351.07$ & $425.67+356.52$ & $127.31+161.93$ \\
\hline Bl4 & $366.50 \pm 256.18$ & $366.50 \pm 256.18$ & $80.57 \pm \overline{5} 6.12$ & $454.75+385.25$ & $452.85 \pm 385.48$ & $105.68 \pm 151.56$ \\
\hline $\mathbf{R}$ & $321.48 \pm 151.36$ & $312.08 \pm 133.00$ & $112.1 \overline{2} \pm 121.76$ & $370.13 \pm 293.93$ & $366.91 \pm 297.26$ & $77.54+\overline{9} 1.86$ \\
\hline $\mathbf{T}$ & $225.85 \pm 146.60$ & $208.92 \pm 138.19$ & $70.23+\overline{5} 4.16$ & $264.31 \pm 294.67$ & $190.18 \pm 217.90$ & $132.5 \overline{3} \pm 307.44$ \\
\hline $\mathbf{k}$ & $6-$ & $6-$ & $6-$ & 6 & 6 & 6 \\
\hline$\alpha$ & .97 & .96 & .85 & .93 & .93 & .80 \\
\hline $\mathrm{ICC}_{2, \mathrm{k}}$ & .97 & .96 & .85 & .92 & .92 & .80 \\
\hline $95 \%$ & $.94-.98$ & $.93-.98$ & $.74-.92$ & $.89-.95$ & $.87-.95$ & $.71-.87$ \\
\hline & & & & & & \\
\hline Bassin $A$ & Inticipation Tim & ing apparatus (B & assin) & & & \\
\hline Bl1 & $86.28 \pm 82.80$ & $76.53+87.29$ & $39.62 \pm 25.47$ & $101.65 \pm 73.84$ & $92.75 \pm 75.63$ & $43.44+34.53$ \\
\hline B12 & $83.87 \pm \overline{7} 70.25$ & $70.67 \pm \overline{ \pm} 81.09$ & $45.69 \pm 27.87$ & $88.36 \pm \overline{6} 0.15$ & $76.28 \pm 66.84$ & $47.21 \pm 29.11$ \\
\hline Bl3 & $92.50 \pm 57.91$ & $72.12 \pm 73.69$ & $45.36 \pm 36.62$ & $92.23 \pm 62.41$ & $81.83 \pm 68.36$ & $40.45 \pm 27.78$ \\
\hline Bl4 & $93.10 \pm 74.05$ & $77.17 \pm \overline{ \pm} 78.40$ & $52.82 \pm 48.77$ & $98.14 \pm 6-64.35$ & $84.29 \pm 74.04$ & $48.22 \pm 27.78$ \\
\hline $\mathbf{R}$ & $88.88 \pm 60.78$ & $85.50 \pm 63.56$ & $33.80 \pm 24.08$ & $98.69 \pm 49.38$ & $90.49 \pm 56.12$ & $35.76+32.01$ \\
\hline $\mathbf{T}$ & $120.0 \overline{4}+46.16$ & $106.4 \overline{3} \pm 53.86$ & $44.67 \pm 26.63$ & $122.9 \overline{3} \pm 98.96$ & $100.1 \overline{3} \pm 78.91$ & $41.18 \pm 27.03$ \\
\hline $\mathbf{k}$ & 6 & 6 & 6 & 6 & 6 & 6 \\
\hline$\alpha$ & .91 & .91 & .67 & .92 & .93 & .72 \\
\hline $\mathrm{ICC}_{2, \mathrm{k}}$ & .91 & .90 & .66 & .91 & .93 & .72 \\
\hline $95 \%$ & $.84-.95$ & $.83-.95$ & $.43-.82$ & $.87-.94$ & $.90-.96$ & $.59-.81$ \\
\hline CI & & & & & & \\
\hline \multicolumn{7}{|c|}{ Bridge + Bassin } \\
\hline $\mathbf{k}$ & 12 & 12 & 12 & 12 & 12 & 12 \\
\hline$\alpha$ & .84 & .81 & .75 & .89 & .89 & .74 \\
\hline $\mathrm{ICC}_{2, \mathrm{k}}$ & .74 & .66 & .72 & .82 & .82 & .73 \\
\hline $\begin{array}{l}95 \% \\
\text { CI }\end{array}$ & $.52-.85$ & $.45-.82$ & $.54-.85$ & $.72-.89$ & $.71-.89$ & $.61-.82$ \\
\hline
\end{tabular}

Note. B11: first five attempts block; B12: second five attempts block; B13: third five attempts block; B14: fourth five attempts block; R: five attempts retention block; T: five attempts transfer block; AE: absolute error; CE: constant error; VE: variable error; $\alpha$ : Crombach's alfa; $\mathrm{ICC}_{2, \mathrm{k}}$ : intraclass correlation coefficient validity between the two methods; CI: confidence interval.

The intraclass correlation coefficient (ICC) between the scores on the six blocks were conducted to examine the convergent validity between Coincident Timing in Team Bridge Games and Bassin Anticipation Timing scores. With exception of CE, ICC showed good to excellent reliability between Bridge and Bassin with ICCs values ranging from 0.66 to 0.74 in the DMD group, and 0.73 to 0.82 in TD group (Table 1).

When observed individually, the ICCs for Bridge and Bassin were excellent, ranging from .66 to .97 , with DMD presented values from .85 to .97 in Bridge. 
Table 3. Pearson correlations between the block results of Bridge Coincident Timing game and Bassin Anticipation Timer at three error, presented by the group of participants

\begin{tabular}{lllllll}
\hline & DMD & & \multicolumn{2}{c}{ TD } \\
& $\mathbf{A E}$ & $\mathbf{C E}$ & $\mathbf{V E}$ & $\mathbf{A E}$ & $\mathbf{C E}$ & $\mathbf{V E}$ \\
\hline $\mathbf{B l 1}$ & $.48^{* *}$ & .17 & -.23 & $.43^{* *}$ & $.38^{* *}$ & .02 \\
$\mathbf{B 1 2}$ & -.07 & -.24 & -.31 & $.48^{* *}$ & $.45^{* *}$ & .07 \\
$\mathbf{B 1 3}$ & $.74^{* *}$ & $.58^{* *}$ & -.18 & $.39^{* *}$ & $.38^{* *}$ & .05 \\
$\mathbf{B 1 4}$ & $.39^{*}$ & $.37^{* *}$ & .01 & $.50^{* *}$ & $.45^{* *}$ & .08 \\
$\mathbf{R}$ & .19 & .14 & -.09 & $.55^{* *}$ & $.49^{* *}$ & .08 \\
$\mathbf{T}$ & -.08 & .03 & -.15 & .23 & .16 & -.11
\end{tabular}

Legend: DMD: Duchenne muscular dystrophy; TD: typical development B11: first block with five attempts; B12: second block with five attempts; B13: third block with five attempts; B14: fourth block with five attempts; R: short-time retest block with five attempts; T: transfer block with five attempts; AE: absolute error; CE: constant error; VE: variable error; *: $p$ value $<.05$; $* *$ : $\mathrm{p}$ value $<.001$

The comparison results between the Bridge and Bassin in terms of the blocks mean differences correlation coefficients for three types of error (AE, CE, and VE) are reported in Table 3. With exception of all transfer blocks, Pearson correlation showed an excellent relationship between blocks for the TD group in AE and CE. The DMD group showed excellent relationship only in $\mathrm{B} 13$ and $\mathrm{B} 14$ for $\mathrm{AE}$ and $\mathrm{CE}$, and no relationship in all blocks of VE.
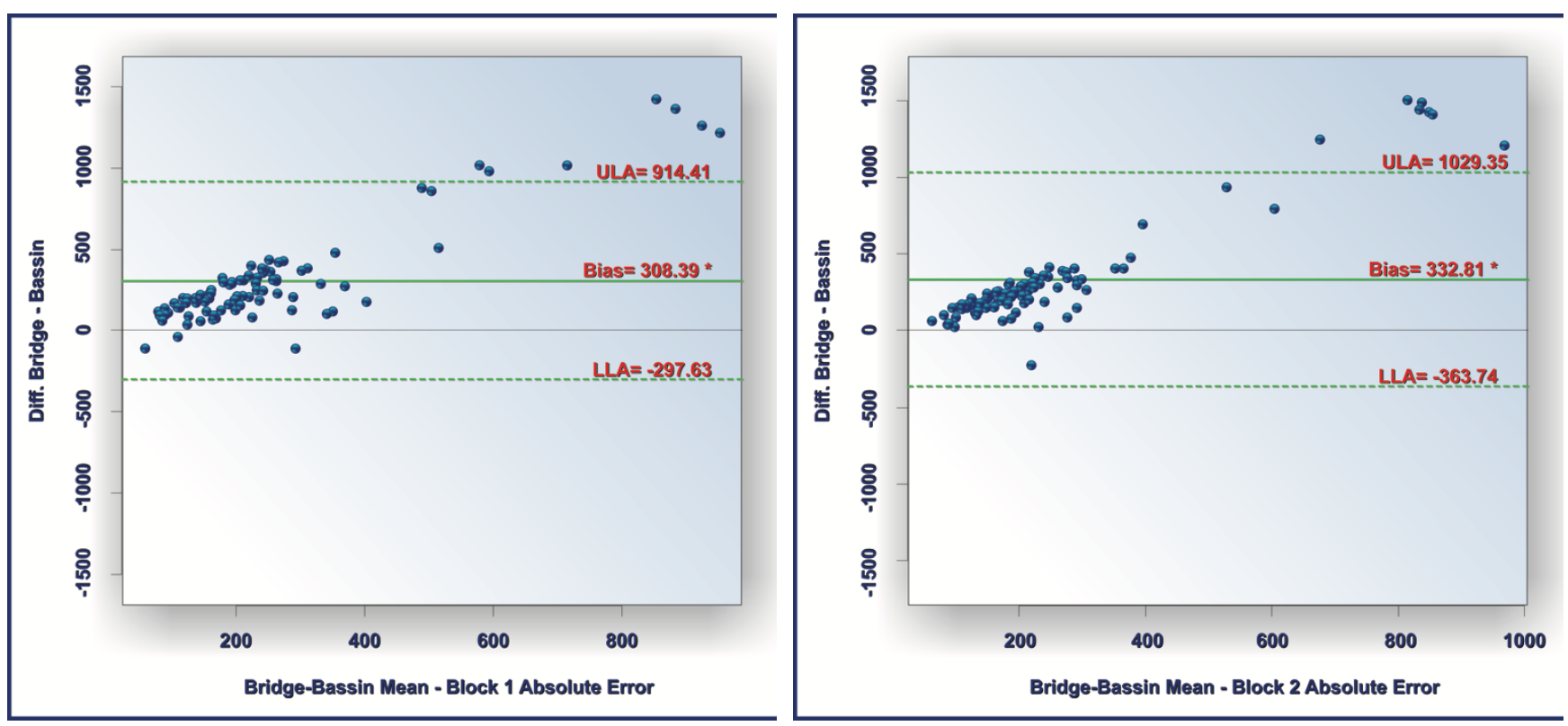

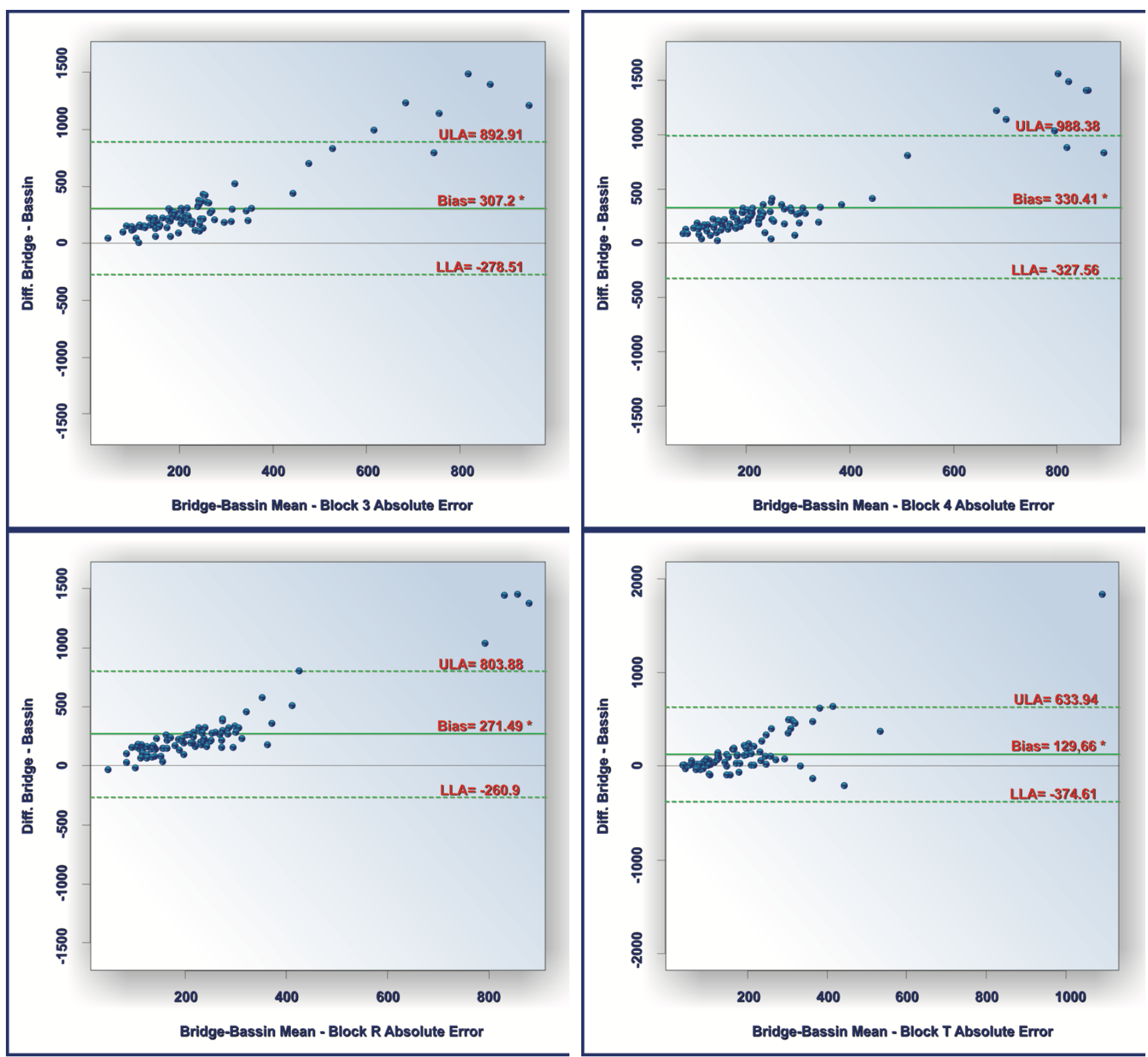

Fig. 4. Bland-Altman plots for averaged block scores of Absolute Error. Solid line systematic bias; dashed lines limits of agreements. (ULA, upper limit of the agreement; LLA, lower limit of agreement).

Overall, the limits of agreement (LoA) between Bridge and Bassin blocks scores for AE were wide. However, Transfer block, with increasing speed, presented the narrowest $95 \%$ of LoA. 


\section{DISCUSSION}

In this study, a validation of a non-immersive virtual reality software to provide the assessment of coincident-anticipation timing (CAT) task was conducted using Duchenne muscular dystrophy participants and healthy males as the control. The main findings of this study were the satisfactory internal consistency and excellent reliability, confirmed by the intraclass correlation coefficient (ICC) values and limit of agreement in Bland-Altman plots in practically all calculated errors.

The results of the study suggested that the Coincident Timing game in Team Bridge game package (Bridge) and Bassin Anticipation Timer (Bassin) do indeed measure a similar construct presented by the concurrent validity of both tests, with ICC values $\geq 0.66$. The Cronbach's alpha above 0.74 reinforces the appropriate homogeneity or correlations of the items and the consistency that both tests measure the same dimension or the theoretical construct ${ }^{42}$. With regard to measurements taken using the Bridge and Bassin CAT task, the reliability results are consistent with previous research which has reported good ICC values when utilizing similar measurement procedures ${ }^{43}$.

The correlations suggest a relationship between Bridge game and Bassin assessment scores, this means that the correlation coefficient is away from 0 . These correlations demonstrate the potential value of Bridge game in clinical assessment of CAT task. The correlations between a new test and the gold standard observed in this study are similar to results seen in other researches. Tong et al. (2016) $)^{44}$ proposed the use of serious games to screen for abnormal cognitive status to conduct validation against standard mental status tools commonly used. They found that the performance on the serious game correlated significantly with the standard tools with $r$ ranged from -0.34 to 0.57 . ${ }^{45}$ found a significantly high correlation between a new video game-driven simulator (Wii Laparoscopy) and an already established instrument test scores, indicating a solid concurrent validity.

It should be noted that Bassin presented lower scores when compared to the Bridge, however, there was no systematic error identifiable in the applied statistical technique that could explain the differences ${ }^{43}$. We can hypothesized that this difference could be due to: (1) a first possibility can be considerate variations in interaction methods wherein Bassin the users used their thumb to press a button instead of an index/middle finger to interact with the computer keyboard; (2) a second possibility is that Bridge game is a composite of subjective vertical visual bubbles (more abstract) and Bassin present a real horizontal LEDs (more real); (3) a third reason can be explained by the difficulty in measuring time on a computer that involves a multitasking operating system such as Windows ${ }^{46}$. Thus, the Bassin is a dedicated apparatus, with hardware designed to work exclusively to control the LEDs and time without the 
interference of others requests to divide its "attention" with another system, as is the case of Windows. On the other hand, the Bridge is a computer program, and it depends on the resolution of the timer and the speed of the computer ${ }^{47}$. Crocetta et al. $(2014)^{48}$ in the validation of a new software to measure the reaction time and compared to a gold standard dedicated hardware, used an external robot to evaluate the computational resources used (operating system, software programming, computer, keyboard, and monitor) to explain the difference founded in both tests.

In contrast, the values of $\alpha$ and ICC in the Bridge were higher than those found in the Bassin, suggesting that the participants were more accurate in Bridge. This happened for both the DMD group and the TD group, confirming the validity of the Bridge. The minimum acceptable value to consider a reliable questionnaire is 0.7 . Values above that promote greater robustness to health research ${ }^{49}$, as well as in our study.

In Table 3 we observed that the correlation was stronger for the advanced blocks of attempts, on the face of it we can say that this correlation may have been due to familiarization with the task, and this became more evident in the retention block. This trend can be observed in the Bland Altman charts, where it can be observed that blocks 1 to 4 present a greater dispersion of points since the retention block has the smallest bias and the lowest limits of agreement.

Despite the positive results in the validity and reliability of the Bridge, some limitations should be presented: (1) the great variability of the patterns and evolution of individuals with DMD, as already observed in other studies with this population ${ }^{30}$; (2) we had difficulty homogenizing the sample due to wide range, thus we use a convenience sample; (3) the lower scores presented in Bassin when compared to Bridge had some hypotheses presented but should be considerate as a limitation.

Despite the limitations, those results are important in practice, the fact that the rehabilitation professional has the possibility of instrument portability. Its ease of use and the practicality that technology can provide, already makes the interest in new studies may suggest and the possibility of an instrument such as this be used in clinical practice gets much bigger. Finally, the Bridge game is a software and it can be portable, so the test could be carried out at the clinics and in different environments. The clinician can at any time use this task to evaluate his patient.

The results suggest that CAT task assessment using the Coincident Timing in Bridge game has a high reliability and is useful in DMD patients. The simplicity of the use of a computer permits the self-administration of CAT assessment by health professionals in nonclinical settings. 


\section{CONCLUSION}

The Coincident Timing game in Team Bridge package presented acceptable reliability and validity been a viable option to coincident-anticipation timing task measurement in Duchenne Muscular Dystrophy participants.

\section{FUNDING}

This work was supported by the Brazilian agency CNPq (Conselho Nacional de Desenvolvimento Científico e Tecnológico) process number 442456/2016-6 and 8887.091039/2014-01.

\section{REFERENCES}

1. Birnkrant DJ, Bushby K, Bann CM, et al. Diagnosis and management of Duchenne muscular dystrophy, part 1: diagnosis, and neuromuscular, rehabilitation, endocrine, and gastrointestinal and nutritional management. Lancet Neurol. Mar 2018;17(3):251267.

2. Walter MC, Reilich P. Recent developments in Duchenne muscular dystrophy: facts and numbers. Journal of cachexia, sarcopenia and muscle. 2017;8(5):681-685.

3. Bushby K, Finkel R, Birnkrant DJ, et al. Diagnosis and management of Duchenne muscular dystrophy, part 1: diagnosis, and pharmacological and psychosocial management. Lancet Neurol. Jan 2010;9(1):77-93.

4. NEISTADT ME, CREPEAU EB. Willard \& Spackman: terapia ocupacional. Nona edição. 2002.

5. Standen PJ, Brown DJ. Virtual reality in the rehabilitation of people with intellectual disabilities: review. Cyberpsychol Behav. Jun 2005;8(3):272-282; discussion 283-278.

6. Fernani DCGL, Prado MTA, Fell RF, et al. Motor intervention on children with school learning dificulties. Journal of Human Growth and Development. 2013;23(2):209-214.

7. Vilozni D, Bar-Yishay E, Gur I, Shapira Y, Meyer S, Godfrey S. Computerized respiratory muscle training in children with Duchenne muscular dystrophy. Neuromuscul Disord. May 1994;4(3):249-255.

8. Capelini CM, da Silva TD, Tonks J, et al. Improvements in motor tasks through the use of smartphone technology for individuals with Duchenne muscular dystrophy. Neuropsychiatr Dis Treat. 2017;13:2209-2217.

9. Monteiro CBD, da Silva TD, de Abreu LC, et al. Short-term motor learning through nonimmersive virtual reality task in individuals with down syndrome. Bmc Neurology. Apr 2017;17.

10. Massetti T, Favero FM, Menezes LDC, et al. Achievement of Virtual and Real Objects Using a Short-Term Motor Learning Protocol in People with Duchenne Muscular Dystrophy: A Crossover Randomized Controlled Trial. Games Health J. Apr 2018;7(2):107-115.

11. Belisle JJ. Accuracy, reliability, and refractoriness in a coincidence-anticipation task. Research Quarterly. American Association for Health, Physical Education and Recreation. 1963;34(3):271-281. 
12. Crocetta TB, Guarnieri R, Antunes TPC, et al. Instruments for Studying CoincidenceAnticipation Timing Task-An Updated Systematic Review. Journal of Physical Education. 2018;5(1):37-52.

13. Clarke ND, Duncan MJ. Effect of Carbohydrate and Caffeine Ingestion on Badminton Performance. Int J Sports Physiol Perform. Jan 2016;11(1):108-115.

14. Duncan MJ, Smith M, Bryant E, et al. Effects of increasing and decreasing physiological arousal on anticipation timing performance during competition and practice. Eur J Sport Sci. 2016;16(1):27-35.

15. Da Gama A, Chaves T, Figueiredo L, Teichrieb V. Guidance and movement correction based on therapeutics movements for motor rehabilitation support systems. Paper presented at: Virtual and Augmented Reality (SVR), 2012 14th Symposium on, 2012.

16. Duncan MJ, Tallis J, Wright SL, Eyre EL, Bryant E, Langdon D. The effect of acute caffeine ingestion on coincidence anticipation timing in younger and older adults. Nutr Neurosci. Sep 2014;17(5):234-238.

17. Forner-Cordero A, Quadrado VH, Tsagbey SA, Smits-Engelsman BC. Improved Learning a Coincident Timing Task With a Predictable Resisting Force. Motor Control. Apr 07 2017:1-31.

18. Ohta $Y$, Nakamoto H, Ishii Y, Ikudome S, Takahashi K, Shima N. Muscle activation characteristics of the front leg during baseball swings with timing correction for sudden velocity decrease. PLoS One. 2014;10(4):e0124113.

19. Cacola P, Ibana M, Ricard M, Gabbard C. Children with developmental coordination disorder demonstrate a spatial mismatch when estimating coincident-timing ability with tools. Res Dev Disabil. Jan 2016;48:124-131.

20. Hurkmans HL, van den Berg-Emons RJ, Stam HJ. Energy expenditure in adults with cerebral palsy playing Wii Sports. Arch Phys Med Rehabil. Oct 2010;91(10):1577-1581.

21. Olivier I, Baker C, Cordier J, Thomann G, Nougier V. Cognitive and motor aspects of a coincidence-timing task in Cerebral Palsy children. Neurosci Lett. Aug 18 2015;602:33-37.

22. Crocetta TB, de Araújo LV, Guarnieri R, et al. Virtual reality software package for implementing motor learning and rehabilitation experiments. Virtual Reality. 2017:111 .

23. Bezerra IMP, Crocetta TB, Massetti $\mathrm{T}$, et al. Functional performance comparison between real and virtual tasks in older adults: A cross-sectional study. Medicine (Baltimore). Jan 2018;97(4):e9612.

24. Crocetta TB, Guarnieri R, Massetti $\mathrm{T}$, et al. Concurrent validity and reliability of alternative computer game for the coincidence anticipation timing task Measurement in Physical Education and Exercise Science; in review.

25. de Mello Monteiro CB, Massetti T, da Silva TD, et al. Transfer of motor learning from virtual to natural environments in individuals with cerebral palsy. Res Dev Disabil. Oct 2014;35(10):2430-2437.

26. Quadrado VH, Silva TDD, Favero FM, Tonks J, Massetti T, Monteiro CBM. Motor learning from virtual reality to natural environments in individuals with Duchenne muscular dystrophy. Disabil Rehabil Assist Technol. Nov 10 2017:1-9.

27. Bellucci Júnior JA, Misue Matsuda L. Construção e validação de instrumento para avaliação do Acolhimento com Classificação de Risco. Revista Brasileira de Enfermagem. 2012;65(5).

28. Rubio DM, Berg-Weger M, Tebb SS, Lee ES, Rauch S. Objectifying content validity: Conducting a content validity study in social work research. Social work research. 2003;27(2):94-104. 
29. de Carvalho EV, Hukuda ME, Escorcio R, Voos MC, Caromano FA. Development and Reliability of the Functional Evaluation Scale for Duchenne Muscular Dystrophy, Gait Domain: A Pilot Study. Physiother Res Int. Sep 2015;20(3):135-146.

30. Hukuda ME, Escorcio R, Fernandes LA, de Carvalho EV, Caromano FA. Evaluation scale development, reliability for sitting and standing from the chair for Duchenne muscular dystrophy. J Mot Behav. 2013;45(2):117-126.

31. Nascimento LP, Martini J, Voos MC, Chien HF, Caromano FA. Development of a new haptic perception instrument: a pilot study. Arq Neuropsiquiatr. Jan 2016;74(1):75-80.

32. Pasquali L. Psychometrics. Revista da Escola de Enfermagem da USP. 2009;43(SPE):992-999.

33. Massetti $T$, Crocetta TB, Guarnieri R, et al. A didactic approach to presenting verbal and visual information to children participating in research protocols: the comic book informed assent. Clinics. 2018;73.

34. Vignos PJ, Jr., Archibald KC. Maintenance of ambulation in childhood muscular dystrophy. J Chronic Dis. Aug 1960;12:273-290.

35. Berard C, Payan C, Hodgkinson I, Fermanian J. A motor function measure for neuromuscular diseases. Construction and validation study. Neuromuscul Disord. Jul 2005;15(7):463-470.

36. Silva $\mathrm{T}$, Monteiro C, Hasue R, et al. Aprendizagem motora em tarefa virtual na Paralisia Cerebral. Temas Desenvolv. 2013;104:47-53.

37. Wolpert DM, Ghahramani Z, Flanagan JR. Perspectives and problems in motor learning. Trends in cognitive sciences. 2001;5(11):487-494.

38. Hirakata VN, Camey SA. Análise de concordância entre métodos de Bland-Altman. Revista HCPA. Porto Alegre. Vol. 29, no. 3 (2009), p. 261-268. 2009.

39. Altman DG, Bland M. Statistics notes: units of analysis. Bmj. 1997;314(7098):1874.

40. Koo TK, Li MY. A Guideline of Selecting and Reporting Intraclass Correlation Coefficients for Reliability Research. J Chiropr Med. Jun 2016;15(2):155-163.

41. Leys C, Ley C, Klein O, Bernard P, Licata L. Detecting outliers: Do not use standard deviation around the mean, use absolute deviation around the median. Journal of Experimental Social Psychology. 2013;49(4):764-766.

42. Maroco J, Garcia-Marques T. Qual a fiabilidade do alfa de Cronbach? Questões antigas e soluções modernas? Laboratório de psicologia. 2006:65-90.

43. Kolber MJ, Pizzini M, Robinson A, Yanez D, Hanney WJ. The reliability and concurrent validity of measurements used to quantify lumbar spine mobility: an analysis of an iphone ${ }^{\circledR}$ application and gravity based inclinometry. International journal of sports physical therapy. 2013;8(2):129.

44. Tong $\mathrm{T}$, Chignell M, Tierney MC, Lee J. A serious game for clinical assessment of cognitive status: validation study. JMIR serious games. 2016;4(1).

45. Jalink M, Goris J, Heineman E, Pierie J, ten Cate Hoedemaker H. Construct and concurrent validity of a Nintendo Wii video game made for training basic laparoscopic skills. Surgical endoscopy. 2014;28(2):537-542.

46. Crocetta TB, Andrade A. Retrasos en la medición del tiempo con el uso de computadoras en la investigación del Tiempo de Reacción. Revista de psicología del deporte. 2015;24(2):0341-0349.

47. Bilski P, Winiecki W. Methods of assessing the time efficiency in the virtual measurement systems. Computer Standards \& Interfaces. 2012;34(6):485-492.

48. Crocetta TB, Viana RL, Silva DE, de Mello Monteiro CB, Arab C, Andrade A. Validity of software for measurement of Total Reaction Time with simple stimulus-TRT_S 2012. Journal of Human Growth and Development. 2014;24(3):295-303. 
49. Streiner DL. Being inconsistent about consistency: When coefficient alpha does and doesn't matter. Journal of personality assessment. 2003;80(3):217-222. 


\section{APÊNDICES}

APÊNDICE A - Currículo Lattes Thaís Massetti

APÊNDICE B - Currículo Lattes Carlos Bandeira de Mello Monteiro 


\section{APÊNDICE A}

\section{Currículo Lattes Thaís Massetti}

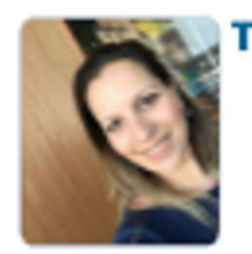

\section{Thaís Massetti}

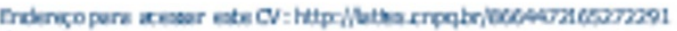

Ut me huleado do arricub ore oq os 2019

Gratuada em Flaberapla, Espedalkta em Doencas Neurcmusalarea, Mestre pela Univeradade de Sto

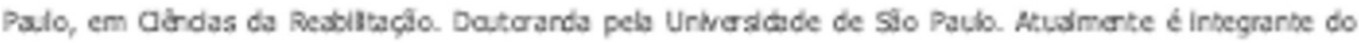

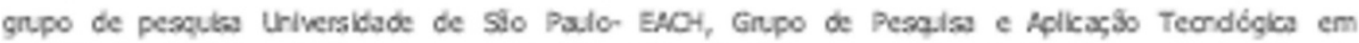

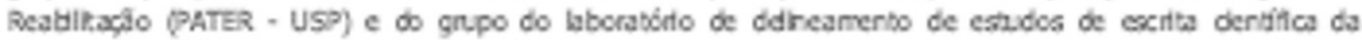
Fauldade de Medicha do ABC. FMASC Tem expertarda na frea de restiltaço com àfare em ilata narobgica e Ortopéda, Escalas de Awalaçb e Folowep (Ganeral Movanents, Aberta Intant Mcta Sale, Test of Intant Mobor Pafomance, Pedatuik Evaluation of Dtabdity Invenbory, Bayky Sales of Intart) CIF

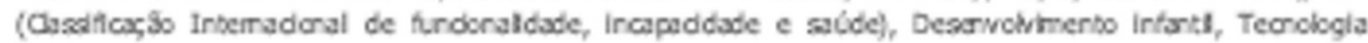
Realstive e Aprendeagem Mobora Realzou viata tócrica na Neuromodilabon Certa at Spasidng Rehablitatton Hosptal, na Harrod Medks. (Texto irf ormato pelo auter)

\section{Identificaçio}

\begin{tabular}{|c|c|}
\hline $\begin{array}{l}\text { Nane } \\
\text { Nane em diaģe bblicgrílicas }\end{array}$ & 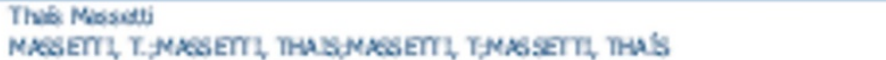 \\
\hline Enderego & \\
\hline Endeneco Frd balenal & 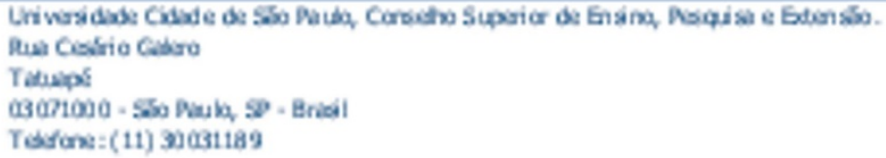 \\
\hline
\end{tabular}

\section{Formação acadêmica/titulação}

\begin{tabular}{|c|c|}
\hline 2015 & 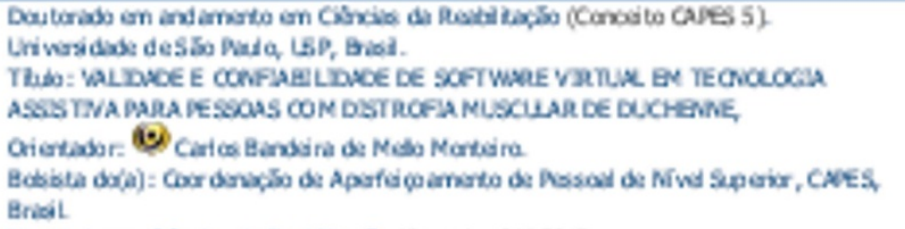 \\
\hline 2012 - 2015 & 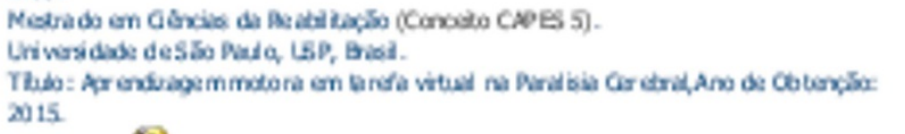 \\
\hline & 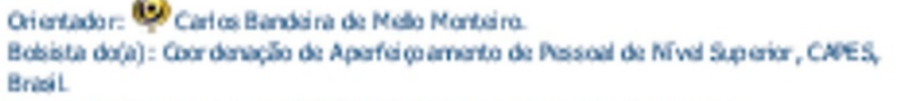 \\
\hline 2015 - 2015 & 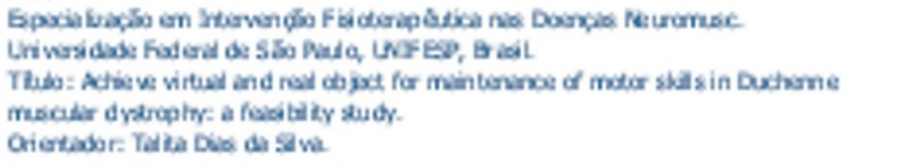 \\
\hline 2012 - 2013 & 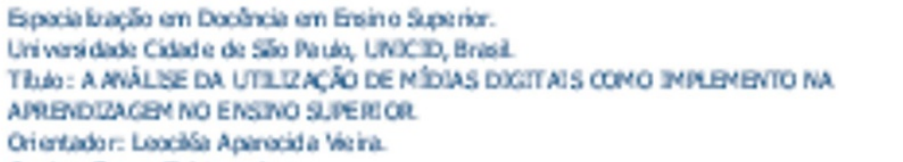 \\
\hline $2012 \cdot 2012$ & 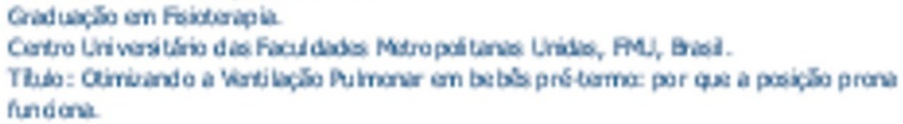 \\
\hline
\end{tabular}




\title{
APÊNDICE B
}

\section{Currículo Lattes Carlos Bandeira de Mello Monteiro}

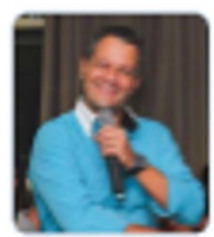

\author{
Carlos Bandeira de Mello Monteiro

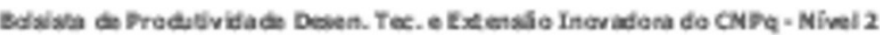

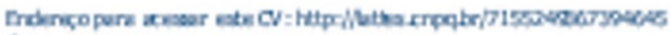

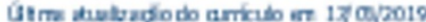

Graduaço em Flaboerapla (1993) e Educaço Fida (1987), Mestre em Dtatitica do Deservohmento pela Uriveradade Prestubertana Makerzie (2001), Doutor em Oèndas ra área de Neurologia pela Univeradade de Şo

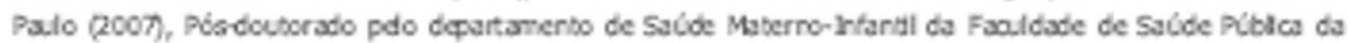
Uriveradade de Sio Palo (2012-2014) con estigio na Vitle Univerkty (Holsoda-2013) e no Naronodulation Cenber at Saubling Rahabatation Hoepital, Haward Melies Schod (2014). Uvie docente pela Uriveradade de

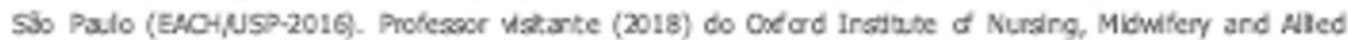

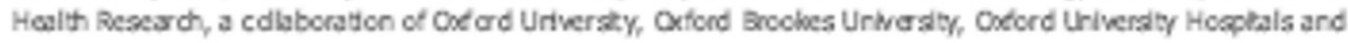
Oxeard Healh NHS Trust Oxford-UK Protesa do arso de Educarbo Fíla e Salde da Esoola de Ater,

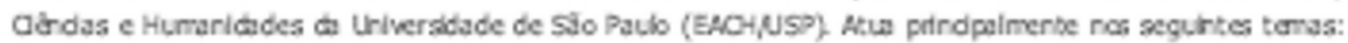

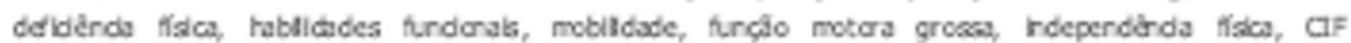

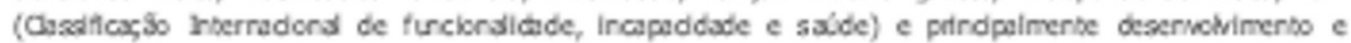

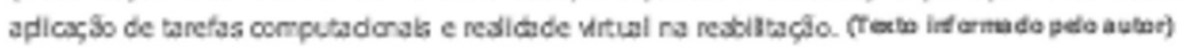

Identificaçio

Nane

Nane em deaçe belicgŕlicas

Carbs Bnderade Mesb Martico

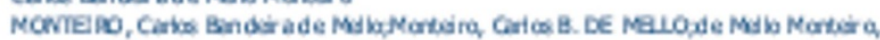

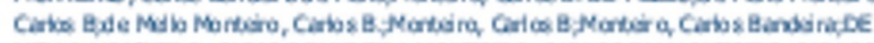

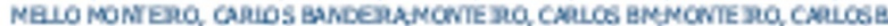

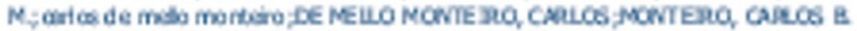

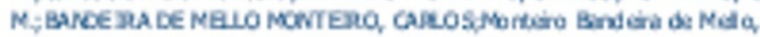

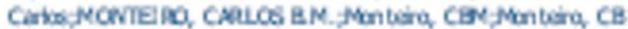

\section{Endereço}

\begin{tabular}{|c|c|}
\hline Endeneco Prod balenal & 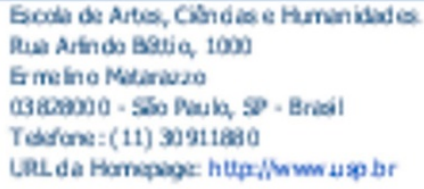 \\
\hline
\end{tabular}

Formação acadêmica/titulação

\begin{tabular}{|c|c|}
\hline $2004-2008$ & 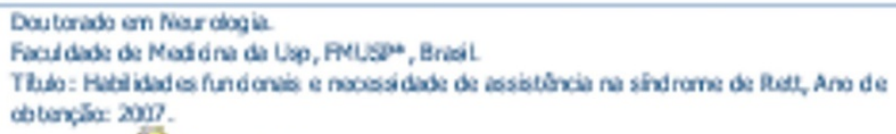 \\
\hline & 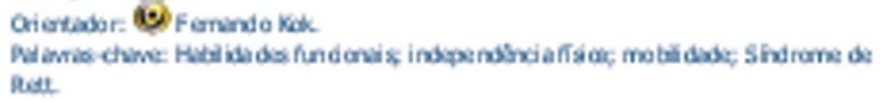 \\
\hline $1929-2002$ & 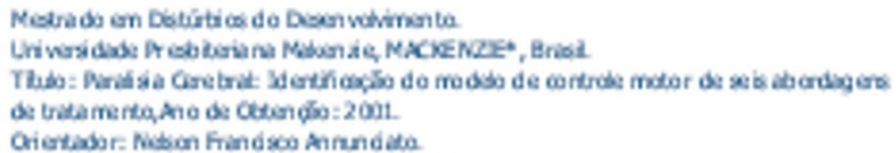 \\
\hline 1992 - 1928 & 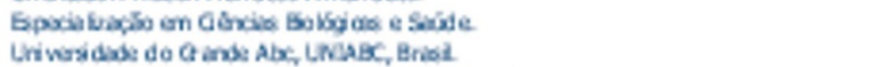 \\
\hline 1988 - $19 a 8$ & 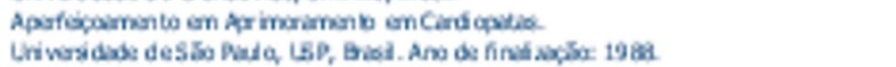 \\
\hline $1990-1923$ & 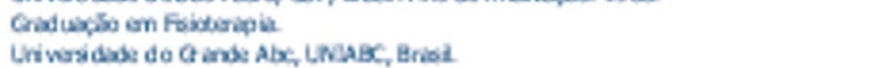 \\
\hline 1985 - 198 & 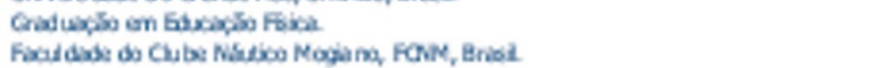 \\
\hline
\end{tabular}

